\title{
Factors Affecting Sustainable Consumer Behavior in the MENA Region: A Systematic Review
}

\author{
Sayed Elhoushy \& Pietro Lanzini
}

To cite this article: Sayed Elhoushy \& Pietro Lanzini (2020): Factors Affecting Sustainable Consumer Behavior in the MENA Region: A Systematic Review, Journal of International Consumer Marketing, DOI: $10.1080 / 08961530.2020 .1781735$

To link to this article: https://doi.org/10.1080/08961530.2020.1781735

\section{曲 Published online: 22 Jun 2020.}

Submit your article to this journal $\square$

Q View related articles $\square$

View Crossmark data ¿ 


\title{
Factors Affecting Sustainable Consumer Behavior in the MENA Region: A Systematic Review
}

\author{
Sayed Elhoushy (D) and Pietro Lanzini \\ Department of Management, Ca' Foscari University, Venice, Italy
}

\begin{abstract}
Sustainable consumer behavior (SCB) gained significant attention given the relevance it bears for a broad set of actors. Since most of the relevant literature is rooted in western countries, researchers and policymakers implicitly assume that behaviors in developing countries tend to replicate those in developed countries. This review, based on seventy-one articles published since 2000, questions such assumption by analyzing the empirical research on SCBs in the Middle East and North Africa (MENA), a distinctive region that has been so far overlooked by mainstream research. Results reveal that most MENA-based papers are rooted in traditional frameworks of the rationalistic stream and that environmental values represent a key driver of SCB, while habits and socio-demographics are relegated to a negligible role. This study provides an added value by synthesizing the fragmented evidence on the topic and discussing aspects emerging as peculiar of the MENA and differentiating the latter from other societies.
\end{abstract}

\section{KEYWORDS}

Middle East and North Africa (MENA); sustainable consumer behavior; systematic review

\section{Introduction}

The growing awareness on the unsustainability of current production and consumption patterns led to widespread consensus over the need to promote a shift in the paradigm capable of avoiding the detrimental impacts that current trajectories entail. While the problematic aspects of the dominant paradigm of development have a long history, they reached center-stage attention quite recently as sustainable production and consumption are now acknowledged as a high priority sustainable development goal for countries worldwide (United Nations 2018). Such a shift requires synergic efforts from actors like industrial companies and public organizations, while also individual citizens are asked to play a prominent role in their daily activities (Caruana and Chatzidakis 2014; Sen, Du, and Bhattacharya 2016). SCB represents the object of a broad and wealthy literature which is by nature interdisciplinary, encompassing studies in the fields of marketing, management, psychology, and sociology (Lanzini 2018), with the relevance on the topic being mirrored by the number of editorial essays (Carrington et al. 2020) and special issues (Ruby, Walker, and Watkins 2020) that journals devote to it.

The present paper analyses SCB in the MENA region, where the consequences of unsustainable behavioral patterns (of which purchase/consumption represents only a single although relevant example) might get exacerbated by the fact that developing countries are currently facing fast rates of development and urbanization, with environmental issues often relegated to the background: "[g]overnmental policies in these economies tend to develop the economy and feed the hungry, rather than consider environmental performance" (Wang et al. 2019, p. 748). Furthermore, the region is hindered by natural constraints, political instability and subsequent financial burdens (Issa and Al Abbar 2015), which represent a distinctive institutional setting that may either facilitate or hinder sustainable consumption.

CONTACT Sayed Elhoushy sayed.elhoushy@unive.it E Department of Management, Ca' Foscari University, Cannaregio 873, Fondamenta San Giobbe, Venice, 30121, Italy.

(C) 2020 Taylor \& Francis Group, LLC 
In parallel, while consumers in western societies have acknowledged and recognized the relevance of the impacts of their behaviors on the environment, consumers in the MENA region are still at the infancy stage of environmental awareness (Khosravi, Jha-Thakur, and Fischer 2019; Mostafa 2006). This discrepancy is also mirrored by the academic world. On the one hand, the need for a cross-cultural approach to the topic is not new, as almost twenty years ago Chan and Lao stressed how "despite the fact that most of the behavioral theories have been developed and tested in western countries, and particularly in the US, relatively little attention has been devoted to investigating their validity in other cultural settings" (Chan and Lau 2002, p. 11). On the other hand, there is still an imbalance in the cultural/geographical representativeness of SCB studies, since "an overwhelming proportion of research continues to be restricted to European and North American consumers. Clearly, a more globally representative understanding of consumer responses to CSR [Corporate Social Responsibility] is called for" (Sen, $\mathrm{Du}$, and Bhattacharya 2016, p. 73).

The predominance of western-based literature, however, should not overshadow the growing literature now available on SCB in emerging economies. Indeed, the interest in the influence of culture on consumer behavior has recently increased, spurred by the globalization of markets and diversification of consumer segments (Douglas and Craig 1997; Scalco et al. 2017). It is indeed reasonable to assume that individual behaviors are guided also by culture-specific factors, so that employing a cultural lens might promote a better understanding of sustainable behaviors and their determinants (Bamberg and Möser 2007; Minton et al. 2018; Thøgersen 2010): recently, a new stream of research "seeks to develop a more culturally oriented understanding, focusing on themes such as social identities, consumption communities and socio-culture factors that determine the nature and scope of (ethical) consumption" (Chatzidakis, Shaw, and Allen 2018, p. 2).

While evidence from developing countries is mostly atomistic, being either focused on a single country or on a cross-national comparison of two or few countries, the present article provides an added value to the literature since, to the knowledge of the authors, no systematic review on SCB in the MENA region (where consumers share multiple cultural, political, and economic aspects that set them apart from other parts of the world) has been performed. To reach its objective, the paper is organized as follows. First, the main theoretical frameworks on the determinants of SCB are presented (Section theoretical frameworks on SCB). Then, Section an overview on SCB research across cultures is angled toward the cross-cultural dimension of $\mathrm{SCB}$, adopting a cultural lens to analyze SCB research across countries and cultural contexts. The methodology for the systematic review is described in Section Methodology, which illustrates the search strategy, the selection criteria and how relevant information has been extracted from included articles and organized for the results' discussion. Section Results is devoted to the description of results emerging from the review of MENA literature. To this end, it has been divided in four subsections focusing on sociodemographic and psychographic variables (5.1), habits and past behavior (5.2), planned behavior (5.3) and altruistic/environmental variables (5.4), respectively. Section Conclusions and future steps is devoted to concluding remarks and to the identification of avenues for future research. With this respect, a guiding framework to be adopted for future studies on the topic is proposed: the framework integrates different predictors from mainstream models into one single coherent framework, with a specific angle toward MENA specificities and cultural factors.

\section{Theoretical frameworks on SCB}

SCB represents a complex and elusive concept, as many different labels have been proposed in literature, according to the specific perspective of analysis; to the end of this paper, SCB is operationalized as a behavior that improves social and environmental performances as well as consumer well-being (Belz and Peattie 2009). A diversity of models and a large variety of variables are considered to have an impact on consumers' sustainable decisions. These can be broadly divided into 
two main streams: one focusing on a rational and aware cognitive process (which can, in turn, be triggered by either egoistic or altruistic motives) and one focusing on the automatic repetition of behaviors and the development of habits (Abrahamse 2019; Lanzini 2018).

With regard to the cognitive stream, the Theory of Reasoned Action (TRA: Fishbein and Ajzen 1975) assumes that intentions represent the main predictor of actual behaviors, and have in turn attitudes and subjective norms as antecedents: while the former represent the general predisposition toward a behavior, the latter are expression of the perceived social pressure. The Theory of Planned Behavior (TPB, Ajzen 1985, 1991) adds perceived behavioral control ${ }^{1}$ (PBC) as a third antecedent of behavioral intentions, overcoming the simplistic assumption that behaviors are always under volitional control. According to Norm-Activation Model (NAM: Schwartz and Howard 1981), personal norms are the key antecedent of behaviors. Personal norms are feelings of moral obligation toward (not) performing an (un)sustainable activity and get activated by awareness of consequences (of not adopting the virtuous behavior) and ascription of responsibility for such detrimental consequences. Connected to NAM is Value-Belief-Norm Theory (VBN, Stern et al. 1999), which again postulates that personal norms are the most prevalent predictor of behavior. The latter is a conjunction of three attitudinal factors (namely values, beliefs, and personal norms), and is driven through a chain of causally related variables: values, worldview, awareness of consequences, ascription of responsibility, and personal norms.

A second stream of research stems from the assumption that behaviors can be at times triggered by an automatic response to a familiar situation, rather than by rational evaluations of available alternatives (Verplanken and Aarts 1999). Habits can be described as a form of goaldirected behavior: that is, as links between a goal and actions that are instrumental in attaining this goal (Aarts and Dijksterhuis 2000). When genuine habits develop, cognitive evaluation of alternatives gets deactivated, and the process is facilitated by conditions, such as frequent repetition, goal-directed automaticity, and stable contexts.

It is plausible to assume that, indeed, both rational evaluations and automatic responses to familiar situations can play a role in shaping behavioral trajectories, with either of the two assuming a predominant role according to the specific individual, behavior and situation at hand. Consistently with this assumption, different theoretical frameworks have been proposed in literature, such as the Theory of Interpersonal Behavior (TIB, Triandis 1977), Attitude-BehaviorContext Theory (ABC, Stern 2000), or the Comprehensive Action Determination Model (CADM, Klöckner and Blöbaum 2010).

\section{An overview on SCB research across cultures}

While the review represents a novelty for the MENA region, there are in literature meta-analyses and systematic reviews focusing on different geographical and cultural contexts. Most of these are based (almost) exclusively on western countries (e.g., Schanes, Dobernig, and Gözet 2018), yet there are studies that include also evidence from developing countries, adopting a cross-cultural lens enabling an analysis of the role of cultural and socio-economic context in shaping behavioral patterns in the domain of sustainability. Such works have been performed with reference both to sustainable behaviors in general (Morren and Grinstein 2016; Papaoikonomou, Ryan, and Valverde 2011) and to specific behavioral domains, ranging from mobility (Lanzini and Khan 2017) to purchasing of green products (Scalco et al. 2017), and recycling (Miafodzyeva and Brandt 2013).

Morren and Grinstein (2016) performed a meta-analysis on sixty-six studies from twentyeight (both developed and developing) countries, testing within the TPB framework the moderating effect of variables such as economic development and national culture. Their analysis confirms the effectiveness of planned behavior constructs for the investigation of SCB, yet highlight the keyrole exerted by the cultural context, as "pro-social behavior, and specifically environmental behavior varies considerably across countries and national cultures when accounting for the TPB 
framework" (Morren and Grinstein 2016, p. 92). For instance, the meta-analysis suggests that there is a broader intention-behavior gap in developing countries, perhaps because of a lack of opportunities to act consistently with pro-social or proenvironmental intentions (e.g., availability of green products in the stores). As a consequence, there is a lower correlation between behavioral intentions and $\mathrm{PBC}$, as people feel less empowered to be sustainable.

Papaoikonomou, Ryan, and Valverde (2011) performed a systematic literature review on empirical studies on SCB. Although the overwhelming majority of the eighty contributions is based either in the US or Europe, some of the papers included in the review are from developing countries such as Turkey, Egypt or India. TPB is confirmed as the most influential framework, although integrations to the original formulation (e.g., inclusion of moral concerns) are common and useful in increasing the predictive capability. The authors stress how future research should be focusing on the role of the social and cultural context, which has been overlooked by the vast majority of literature on SCB whereas "[t]he cultural context $(\ldots)$ is important because it shapes ethical beliefs and moral values" (Papaoikonomou, Ryan, and Valverde 2011, p. 214).

Lanzini and Khan (2017) performed a metaanalysis on the psychological and behavioral determinants of modal choice. TPB and NAM emerge as the key theoretical frameworks adopted in studies in the mobility domain, while also habits are analyzed in a considerable number of studies, probably given the fact that most commuting trips represent a repetitive behavior, on the same route and in a stable context. Most included studies focused on samples from developed countries, with the notable exception of Taiwan (two studies out of fifty-eight), and sample country did not emerge as significant in the moderator analysis performed to gain insights on the high heterogeneity of results.

In a meta-analysis on the purchase of green products, Scalco et al. (2017) analyze seventeen studies adopting the TPB framework, based on samples from heterogeneous geographical contexts and cultural backgrounds. Two out of three samples from developing countries (India and Iran) are those showing the weakest correlation between subjective norms and the intention to purchase organic food. Further, consistently with Morren and Grinstein (2016) the link between PBC and behavioral intentions is weaker in developing countries.

Miafodzyeva and Brandt (2013) performed a meta-analysis on recycling behaviors, analyzing sixty-three studies from seventeen countries including Uganda, Mexico, Bangladesh, Hong Kong and Korea. According to the results, moral norms and environmental concern emerge as key behavioral determinants, while socio-demographic factors play only a marginal role, although religious identity (Kurz, Linden, and Sheehy 2007) might in some cases be relevant.

\section{Methodology}

This paper adopted the approach of Tranfield, Denyer, and Smart (2003) in conducting the systematic review aimed at identifying the factors that influence SCB in MENA countries.

\section{Search strategy}

The strategy consisted of searching for relevant studies in the scientific literature, focusing on behavioral domains that are considered by most literature as relevant from a sustainability standpoint (Thøgersen and Ölander 2003). The search strings ${ }^{2}$ were based on the combination of (SCBs (X) AND MENA countries (X)). The different SCBs and MENA countries were inserted into $\mathrm{X}$, one at a time, surfing six research databases and search engines: Scopus, ScienceDirect, EBSCO, Egyptian Knowledge Bank, Masader-Oman Virtual Science Library and Google Scholar. However, in order to make sure all relevant articles were included, a supplementary strategy was adopted and consisted of a) cross-reference search of all collected articles, b) hand searching in social platforms including Academia and Research Gate, and c) contacting the researcher in case full text was not available online.

\section{Selection criteria}

Selection criteria required that papers had to a) focus on the determinants of SCB, b) be 
conducted in one of MENA countries ${ }^{3}$, and c) be published in 2000 or later. More in detail, articles have been initially selected if the search terms appeared in the topic section of the database or in the keywords, title or abstract of the article. Then, manual analysis of each paper has been performed to identify whether it actually focused on the topic being investigated, and whether it matched the quality standards, using journal ranking as an indicator or manually in case of papers published in regional journals with no impact factor. Of the 5,786 articles selected, seventy-one could be retained based on the aforementioned criteria, and represent the sample of the review $(n=71)$. Each study in the final sample is indexed in Table 1.

\section{Analysis}

To synthesize this literature, we analyzed the content of the sampled studies, retrieving and tabulating from each article: study profile (i.e., year, author(s), journal, study objectives, theoretical background, setting, and sample specifications, data collection tools, outcome variable, determinants of the outcome variable, and other key findings relevant to the review.

Stemming from the objectives of this study, papers were grouped in terms of the outcome variable (e.g., waste reduction, green purchase) and the direct antecedents of this outcome variable. Then, the most prominent variables in the MENA countries were identified and mirrored in relation to the key theoretical frameworks to highlight (in)consistencies with mainstream literature.

The increase in the number of publications in the analyzed period has been substantial over the last five years, with researchers beginning to show interest in the topic. SCB research in MENA countries is unevenly distributed: while the majority of SCB studies were conducted in Iran (twenty-six papers), followed by Egypt and Lebanon (nine papers each), six out of the eighteen sampled countries had no publications at all.

Sample studies were grouped into five behavioral categories based on the outcome variable. The single most studied behavior is green purchase, followed by generic sustainable behaviors, organic food, energy savings, and waste management/recycling. The "others" category includes a heterogeneous set of behavioral domains which have received very little attention so far yet are likely to assume increasing relevance in future years (e.g., sustainable mobility).

\section{Results}

The present section illustrates in detail the results of the review. Table 1 lists all papers included in the latter, describing main features, such as sample details (size, type, and geographical location), behaviors being investigated (i.e., the outcome variable), variables that are supposed to be their antecedents (i.e., the predictors) and the relationship found which can be positive, negative, or not significant. Table 2, on the other hand, illustrates the main predictors (listed in order of prevalence in the sample), detailing for each one of them how many studies found a positive, negative or not significant relationship with the outcome variables, respectively.

This section is organized as to illustrate results referring to (1) socio-demographics and psychographic variables; (2) habits and past behavior; (3) planned behavior variables and (4) altruistic and environmental variables.

\section{Socio-demographics and psychographic variables}

Socio-demographic variables have been object of most early studies on SCB and are present in relevant numbers also in the dataset pertaining to MENA countries. Consistently with prior evidence in literature (Diamantopoulos et al. 2003; Lanzini 2018), socio-demographic variables do not emerge as good predictors of sustainable behaviors: there is indeed no consensus on the effects of GEIA (gender, education, income, and age) on SCBs.

The demographic variable that received most attention is represented by gender, which is consistent with the speculation that in maleempowered societies such as MENA countries it could play a relevant role. Gender is analyzed in twenty-four studies of the sample and appears to be a significant behavioral antecedent in twelve of these; yet, there is no agreement whether it is men or women that show virtuous behavioral patterns. Although a prevalence of studies 
Table 1. Sample studies - key figures.

\begin{tabular}{lccc}
\hline$\#$ & Article & Sample size, type, Country & Outcome vartecycling \\
\hline 1 & Aktas et al. (2018) & $\begin{array}{c}277 \text { consumers, } \\
\text { convenience, Qatar }\end{array}$ & Waste/recy \\
2 & Abdelradi (2018) & $\begin{array}{c}1000 \text { consumers, } \\
\text { convenience, Egypt }\end{array}$ & Waste/recycling \\
3 & Babaei et al. (2015) & $\begin{array}{c}2400 \text { householders, } \\
\text { random, Iran }\end{array}$ & Waste/recycling \\
4 & Mattar et al. (2018) & $\begin{array}{c}1264 \text { interviews }+250 \text { dairy } \\
\text { sheets of consumers, } \\
\text { convenience, Lebanon }\end{array}$ & Waste/recycling
\end{tabular}

$5 \quad$ Pakpour et al. (2014)

1782 households, random, Iran

$6 \quad$ Asif et al. (2018)

7 Bagher, Salati, and Ghaffari (2018)

8 Charbaji and Hayek (2003)

9 Haghjou et al. (2013)

10 Minbashrazgah, Maleki, and Torabi (2017)

11 Mohamed, Chymis, and Shelaby (2012)

12 Muhammad, Fathelrahman, and Ullah (2015)

13 Nedra, Sharma, and Dakhli (2015)

14 Rahnama (2017)

15 Sadati and Mohammadi (2012)

16 Saleki, Seyedeh, and Rahimi (2012)

17 Yazdanpanah and Forouzani (2015)

18 Yazdanpanah, Forouzani, et al. (2015)

19 Zarei and Maleki (2018)

20 Almossawi (2014)

21 Al-Otoum and Nimri (2015)

22 Attia (2014)

23 Attia and Farrag (2017)
203 students, purposeful, Lebanon.

313 consumers, -, Iran

220 consumers, convenience, Iran

215 consumers, random, Iran

423 consumers, convenience, Iran

282 consumers, random, Iran

200 mixed, convenience, Egypt

300 consumers, random, UAE

350 consumers, convenience, Tunisia

483 female consumers, convenience, Iran

174 consumers, convenience, Iran

150 consumers, random, Iran

389 students, stratified random sampling, Iran

389 students, stratified random, Iran.

243 students, Convenience, Bahrain

342 consumers, convenience, Jordan

89 students, convenience, Egypt

138 consumers, random, Egypt
Waste/recycling

Organic food/products

Organic food/products

Organic food/products

Organic food/products

Organic food/products

Organic food/products

Organic food/products

Organic food/products

Organic food/products

Organic food/products

Organic food/products

Organic food/products

Organic food/products

Organic food/products

Green purchase

Green purchase

Green purchase

Green purchase
Predictors

Attitude (+), Food surplus (+), Lack of perceived behavioral control $(+)$, Ramadan $(+)$, Subjective norm (+), Intention (-), Lack of perceived behavioral control (-).

Food choice (healthy and safety) $(+)$, Materialism $(+)$, Waste minimization $(+)$, Waste recycling $(-)$, Environmental awareness (n.s), Food expenditure (n.s), Personality (n.s).

Age $(+)$, Education $(+)$, Gender (+), Occupation (+).

Area (rural vs. urban) $(+)$, Education $(+)$, Feeling guilty when throw food away $(+)$, Incentives $(+)$, Prepare different dishes each day $(+)$, Think of ways to use leftovers $(+)$, Buy special offers (-), Eating out (-), Employment status (-), Family size (-).

Action planning $(+)$, Attitude $(+)$, Age $(+)$, Gender $(+)$, Intention $(+)$, Moral obligation $(+)$, Past behavior $(+)$, PBC $(+)$, Self-identity $(+)$, Subjective norms (+), Education (n.s).

Attitude $(+)$, Environmental awareness $(+)$, Environmental concern $(+)$, Health consciousness $(+)$, Subjective norm (+), PBC (n.s).

Attitude $(+)$, Environmental concern $(+)$,

Environmental knowledge $(+)$, Ethical orientation $(+)$, Health awareness $(+)$, Health lifestyle $(+)$, PBC $(+)$, Subjective norm $(+)$.

Education (+), Environmental concern $(+)$, Gender $(+)$, Health concern $(+)$, Animal welfare (n.s), Governmental standards (n.s).

Attitude (+), Environmental knowledge $(+)$, Food-born risk perception $(+)$, General shopping criteria $(+)$ Gender $(+)$, Marital status $(+)$, Family size $(+)$, Income (+), Age (n.s), Education (n.s).

Intention $(+)$, Organic food belief $(+)$, Perceived environmental responsibility $(+)$, Trust $(+)$, Price transparency (-), Subjective norm (n.s).

Age (+), Income (+), Education (n.s), Gender (n.s), Number of children (n.s).

Age $(+)$, Education $(+)$, Household Size $(+)$, Income $(+)$, Nationality $(+)$, Environmental awareness (n.s), Employment status (n.s.), Gender (n.s).

Environmental concern $(+)$, Health concern $(+)$, Implication (+), Intention (+), Attitude (n.s).

Conditional value $(+)$, Epistemic value $(+)$, Functional value $(+)$, Health value $(+)$, Environmental value (n.s), Emotional value (n.s), Social value (n.s),

Attitude $(+)$, PBC $(+)$, Subjective norm $(+)$.

Attitude $(+)$, Environmental knowledge $(+)$, Subjective norm (n.s).

Area (urban vs. rural) $(+)$, Attitude $(+)$, Gender $(+)$, Moral norms (+), Self-identity (+), PBC (n.s), Subjective norms (n.s)

Area (urban vs. rural) $(+)$, Gender $(+)$, General health orientation (+), Perceived benefits (+), Self-efficacy $(+)$, Perceived barriers (-), Cues to action (n.s), Education (n.s), Perceived severity (n.s), Perceived susceptibility (n.s).

Attitude (+), Corporate ability (+), Information seeking $(+)$, Intention (+), Environmental knowledge (n.s), Green skepticism (n.s)

Attitude (+), Environmental concern (+), Environmental knowledge $(+)$.

Education $(+)$, Environmental awareness $(+)$, Income $(+)$, Trust (+), Age (n.s).

Attitude $(+)$, Green advertising (+).

Consumer lifestyle (+), Consumer values (-), Age (n.s), Education (n.s), Gender (n.s), Income (n.s). 
Table 1. Continued.

\begin{tabular}{|c|c|c|c|}
\hline$\#$ & Article & Sample size, type, Country & Outcome va \\
\hline 24 & Dagher and Itani (2014) & $\begin{array}{l}101 \text { consumers, } \\
\text { Convenience, Lebanon }\end{array}$ & Green purchase \\
\hline 25 & $\begin{array}{l}\text { Dagher, Itani, and } \\
\text { Kassar (2015) }\end{array}$ & 326 consumers, -, Lebanon & Green purchase \\
\hline 26 & $\begin{array}{l}\text { Dehghanan and } \\
\text { Bakhshandeh (2014) }\end{array}$ & $\begin{array}{l}412 \text { consumers, } \\
\text { convenience, Iran }\end{array}$ & Green purchase \\
\hline 27 & $\begin{array}{l}\text { Esmaeilpour and } \\
\text { Bahmiary (2017) }\end{array}$ & $\begin{array}{l}315 \text { consumers, } \\
\text { convenience, Iran. }\end{array}$ & Green purchase \\
\hline 28 & Grace and Omar (2012) & 101 consumers, -, Lebanon. & Green purchase \\
\hline 29 & $\begin{array}{l}\text { Ibrahim and Al- } \\
\text { Ajlouni (2018) }\end{array}$ & $\begin{array}{l}471 \text { students, convenience, } \\
\text { Saudi Arabia }\end{array}$ & Green purchase \\
\hline
\end{tabular}

30 Khorshidi, Gholizadeh, and Naghash (2014)

31 Mobrezi and Khoshtinat (2016)

32 Mostafa (2006)

34 Mostafa (2009)

35 Mourad and Serag Eldin Ahmed (2012)

36 Nejati, Salamzadeh, and Salamzadeh (2011)

37 Rahnama and Rajabpour (2017)

38 Siyavooshi, Foroozanfar, and Sharifi (2019)

39 Vazifehdoust et al. (2013)

40 Zare, Bagheri, and Moein (2016)

41 Zu'bi et al. (2015)

42 Abdul-Muhmin (2007)

43 Akermi and Smaoui (2016)

44 Alsmadi (2007)

45 Bhuian et al. (2018)

46 Kalantari and Asadi (2010)

47 Khan and Trivedi (2015)

48 Makki, Abd-El-Khalick, and BouJaoude (2003)

49 Mkik, Khouilid, and Aomari (2017)

50 Nassani et al. (2013)

51 Oweini and Houri (2006)

\section{2 consumers, random, Iran \\ 279, Female Consumers, -, Iran \\ 1093 students, Convenience, Egypt \\ Green purchase \\ Green purchase \\ Green purchase}

1093 students, convenience, Egypt

418 consumers, convenience, Kuwait

302 consumers convenience, Egypt

274 students, convenience, Iran

700 consumers, convenience, Iran

270 consumers, nonrandom assignment, Iran

374 consumers, convenience, Iran

180 students, stratified random, Iran

250 consumers, convenience, Jordon

232 consumers, Convenience,

Saudi Arabia

14 interviews +275 surveys with consumers, Quota sampling, Tunisia

303 students, convenience, Jordan

306 consumers, Convenience, Oman.

1200 consumers, stratified random, Iran

115 consumers, -, UAE 660 students, stratified sampling, Lebanon.

202 consumers, convenience, Morocco

364 Consumers, -, Saudi Arabia

255 students, convenience, Lebanon

Green purchase

Green purchase

Green purchase

Green purchase

Green purchase

Green purchase

Green purchase

Green purchase

Green purchase

Generic

Generic
Generic sustainable behavior

Generic sustainable behavior Generic sustainable behavior

Generic sustainable behavior Environmental knowledge $(+)$, Environmental value $(+)$, Religiosity (+).

Generic sustainable behavior Attitude $(+)$, Environmental knowledge $(+)$,

Environmental legislation (+), Feeling of stress $(+)$, Preparedness to act $(+)$.

Generic sustainable behavior Gender $(+)$.

Affect (+), Attitude (+), Intention (+).

sustainable behavior

Generic sustainable behavior Environmental awareness (+), Green advertising (+), Age (n.s), Education (n.s), Gender (n.s),

Generic sustainable behavior Consumer Environmental Activism (+).

sustainable behavio
Gender (+), Frequency of hiking (+), Age (n.s), Living abroad (n.s), Major (n.s). 
Table 1. Continued.

\begin{tabular}{|c|c|c|c|c|}
\hline \# & Article & Sample size, type, Country & Outcome variable ${ }^{5}$ & Predictors \\
\hline 52 & Rice (2006) & $\begin{array}{l}330 \text { mixed, } \\
\text { Convenience, Egypt }\end{array}$ & Generic sustainable behavior & $\begin{array}{l}\text { Family size }(+) \text {, Marital status }(+) \text {, Negative } \\
\text { consequences }(+) \text {, Occupation }(+) \text {, Personal } \\
\text { responsibility }(+) \text {, Religiosity }(+) \text {, Self-efficacy }(+) \text {, } \\
\text { Age }(\mathrm{n} . \mathrm{s}) \text {, Gender }(\mathrm{n} . \mathrm{s}) \text {, Education }(\mathrm{mx}) \text {, } \\
\text { Conservation values }(\mathrm{mx}) \text {, Openness to Change } \\
(\mathrm{mx}) \text {, Self-enhancement values }(\mathrm{mx}) \text {, Self- } \\
\text { transcendent values }(\mathrm{mx}) \text {. }\end{array}$ \\
\hline 53 & Sharif (2016) & $\begin{array}{l}7 \text { experts }+243 \text { mixed, } \\
\text { convenience, Qatar. }\end{array}$ & Generic sustainable behavior & $\begin{array}{l}\text { Consumption ethics }(+) \text {, Environmentalism }(+) \text {, Fair } \\
\text { trade attitude }(+) \text {, Materialism (n.s). }\end{array}$ \\
\hline 54 & Tamer (2011) & $\begin{array}{l}241 \text { students, } \\
\text { convenience, Bahrain }\end{array}$ & Generic sustainable behavior & $\begin{array}{l}\text { Education }(+) \text {, Environmental concern }(+) \text {, Income } \\
(+) \text {, Liberalism }(+) \text {, Perceived consumer } \\
\text { effectiveness }(+) \text {, Age }(-) \text {, Gender (n.s). }\end{array}$ \\
\hline 55 & Yaghi and Alibeli (2017) & $\begin{array}{l}1282 \text { consumers, } \\
\text { random, UAE }\end{array}$ & Generic sustainable behavior & $\begin{array}{l}\text { Attitude }(+) \text {, Environmental knowledge }(+) \text {, Education } \\
(+) \text {, Mother's education }(+) \text {, Moral values }(+), \\
\text { Social dilemma (-), Age (n.s), Father's education } \\
\text { (n.s), Gender (n.s), Income (n.s). }\end{array}$ \\
\hline 56 & $\begin{array}{l}\text { Ibrahim and Al- } \\
\text { Ajlouni (2018) }\end{array}$ & $\begin{array}{l}1350 \text { students, } \\
\text { convenience, UAE }\end{array}$ & Water & $\begin{array}{l}\text { Emotion }(+) \text {, Habits }(+) \text {, Awareness/knowledge }(+) \text {, } \\
\text { Attitude }(+) \text {, Social norms }(+) \text {, Facilitating factors } \\
(+) \text {, Religiosity }(+) \text {. }\end{array}$ \\
\hline 57 & Wells et al. (2016) & $\begin{array}{l}447 \text { consumers (Employees)/ } \\
\text { purposef-ul, Iran }\end{array}$ & Energy\& water & Attitude $(+)$, Generativity (+), Age (n.s), Gender (n.s). \\
\hline 58 & Akroush et al. (2019)9 & $\begin{array}{l}474 \text { consumers, non- } \\
\text { probability (convenience } \\
\text { and quota), Jordan }\end{array}$ & Energy & $\begin{array}{l}\text { Attitude }(+) \text {, Environmental awareness }(+) \text {, Perceived } \\
\text { benefits }(+) \text {. }\end{array}$ \\
\hline 59 & Azar and Al Ansari (2017) & $\begin{array}{l}333 \text { consumers, } \\
\text { convenience, UAE }\end{array}$ & Energy & $\begin{array}{l}\text { Discussion of energy conservation with work } \\
\text { colleagues }(+) \text {, Incentives }(+) \text {, Knowledge }(+) \text {, } \\
\text { Level of control }(+) \text {, Motivation e.g., cost reductions } \\
(+) \text {, Pro-environmental communication at home } \\
(+) \text {, Willingness to save energy }(+) \text {, Motivation e.g., } \\
\text { pollution reduction (-), Nationality (-), Occupation } \\
\text { (-), Pro-environmental communication at work (-), } \\
\text { Age (n.s). }\end{array}$ \\
\hline 60 & Düştegör et al. (2018) & $\begin{array}{l}228 \text { Households, } \\
\text { convenience, } \\
\text { Saudi Arabia. }\end{array}$ & Energy & $\begin{array}{l}\text { Environmental knowledge }(+) \text {, Past experience }(+) \text {, } \\
\text { Perceived benefits }(+) \text {, Perceived self-effectiveness } \\
(+) \text {, Environmental awareness (n.s), Social } \\
\text { interaction (n.s.). }\end{array}$ \\
\hline 61 & $\begin{array}{l}\text { Elmustapha, Hoppe, and } \\
\text { Bressers (2018) }\end{array}$ & $\begin{array}{l}200 \text { consumers, } \\
\text { convenience, Lebanon }\end{array}$ & Energy & $\begin{array}{l}\text { Consumer novelty seeking (+), Observability }(+) \text {, } \\
\text { Relative advantage }(+), \text { Total independent } \\
\text { judgment making }(+) \text {, Compatibility (n.s), } \\
\text { Complexity (n.s), Risk (n.s.), Financial Incentives } \\
\text { (n.s), Personal norms (n.s), Subjective norms (n.s), }\end{array}$ \\
\hline 62 & Nahiduzzaman et al. (2018) & $\begin{array}{l}88 \text { households, random, } \\
\text { Saudi Arabia. }\end{array}$ & Energy & $\begin{array}{l}\text { Building area (n.s), Education (n.s), Environmental } \\
\text { awareness (n.s), Family size (n.s), Female proportion } \\
\text { (n.s), Proportion of adults (n.s), Quality of life (n.s). }\end{array}$ \\
\hline 63 & $\begin{array}{l}\text { Rezaei and } \\
\quad \text { Ghofranfarid (2018) }\end{array}$ & $\begin{array}{l}280 \text { households, multistage } \\
\text { sampling, Iran }\end{array}$ & Energy & $\begin{array}{l}\text { Attitude }(+) \text {, Environmental awareness }(+) \text {, Moral } \\
\text { norms }(+) \text {. Relative advantage }(+), \operatorname{PBC}(+), \\
\text { Subjective norms (n.s). }\end{array}$ \\
\hline 64 & $\begin{array}{l}\text { Yazdanpanah, } \\
\text { Komendantova, } \\
\text { et al. (2015) }\end{array}$ & 260 students, random, Iran. & Energy & $\begin{array}{l}\text { Environmental concern (+), Perceived benefits }(+) \text {, } \\
\text { Self-efficacy }(+), \text { Cues to action (n.s), General } \\
\text { concern (n.s), Perceived barriers (n.s), Perceived } \\
\text { severity (n.s), Perceived susceptibility (n.s). }\end{array}$ \\
\hline 65 & Al-Thawadi (2018) & $\begin{array}{l}30 \text { students for experiment } \\
+300 \text { questionnaire, } \\
\text { non-probability, Bahrain. }\end{array}$ & Algal consumption & $\begin{array}{l}\text { Food neo-phobia }(+) \text {, Perceived risk and uncertainty } \\
(+) \text {, Subjective norm }(+) \text {. }\end{array}$ \\
\hline 66 & Mahadin (2018) & $\begin{array}{l}333 \text { consumers, } \\
\text { random, Jordan }\end{array}$ & Green Mobility & $\begin{array}{l}\text { Eco-Friendliness }(+) \text {, Current trend }(+) \text {, Fuel } \\
\text { consumption efficiency }(+) \text {, Technological Features } \\
(+) \text {, Agreeing to switch }(-) \text {, Battery life }(-) \text {, Fear of } \\
\text { technology }(-) \text {, Lack of Information }(-) \text {, Limited } \\
\text { choice of vehicles }(-) \text {, Lower Taxes }(+) \text {, } \\
\text { Overwhelming Trend (-), Price (n.s). }\end{array}$ \\
\hline 67 & $\begin{array}{l}\text { Michel, Nancy, and } \\
\text { Atef (2014) }\end{array}$ & $\begin{array}{l}296 \text { consumers, non- } \\
\text { probability, Lebanon }\end{array}$ & $\begin{array}{l}\text { Green mobile } \\
\quad \text { telecommunication }\end{array}$ & Attitude $(+)$, PBC $(+)$, Subjective norm $(+)$. \\
\hline 68 & Dezdar (2017) & $\begin{array}{l}633 \text { students, } \\
\text { convenience, Iran. }\end{array}$ & $\begin{array}{l}\text { Green } \\
\quad \text { information technology }\end{array}$ & $\begin{array}{l}\text { Attitude }(+) \text {, Consideration of future consequences }(+), \\
\text { Intention }(+) \text {, Openness to experience }(+), \text { PBC }(+), \\
\text { Subjective norm }(+) \text {. }\end{array}$ \\
\hline 69 & Mostafa (2016) & $\begin{array}{l}1212 \text { consumers, } \\
\text { Convenience, Egypt. }\end{array}$ & $\begin{array}{l}\text { WTP premium for carbon- } \\
\text { labelled products }\end{array}$ & Gender $(+)$, Income $(+)$, Age $(-)$, Education (-). \\
\hline 70 & $\begin{array}{l}\text { Mostafa and Al- } \\
\text { Hamdi (2016) }\end{array}$ & $\begin{array}{l}246 \text { consumers, } \\
\text { convenience, Kuwait }\end{array}$ & $\begin{array}{l}\text { WTP for Environmental } \\
\text { protection (leisure) }\end{array}$ & $\begin{array}{l}\text { Income (+), Price (-), Age (n.s), Education (n.s), } \\
\text { Gender (n.s). }\end{array}$ \\
\hline 71 & Baqer (2012) & $\begin{array}{l}251 \text { students, } \\
\text { convenience, Kuwait }\end{array}$ & $\begin{array}{l}\text { Willingness to share } \\
\text { environmental } \\
\text { responsibility }\end{array}$ & $\begin{array}{l}\text { Business support (+), Environmental concern (+), } \\
\text { Environmental consciousness }(+) \text {, Government } \\
\text { support }(+), \text { Locus of control }(+), \text { Media }(+), \\
\text { Spiritual beliefs }(+) \text {, Skepticism (n.s). }\end{array}$ \\
\hline
\end{tabular}


Table 2. MENA prominent SCB predictors.

\begin{tabular}{lll}
\hline Main predictors* & \# of studies (Effect) & Relevant theories \\
\hline Attitudes & $29(+), 1(-), 2(\mathrm{n} . \mathrm{s})$ & TPB \\
Gender & $12(\mathrm{sig}),. 12(\mathrm{n} . \mathrm{s})$ & Socio-demographics \\
Age & $4(+), 4(-), 12(\mathrm{n} . \mathrm{s})$ & Socio-demographics \\
Education & $8(+), 2(-), 1(\mathrm{mx}), 9(\mathrm{n} . \mathrm{s})$ & Socio-demographics \\
Subjective norms/social influence & $12(+), 6(\mathrm{n} . \mathrm{s})$ & TPB \\
Environmental concern & $16(+), 1(\mathrm{n} . \mathrm{s})$ & VBN \\
PBC/self-efficacy & $12(+), 2(\mathrm{n} . \mathrm{s})$ & TPB/ Health Belief Model \\
Intentions & $12(+), 1(-)$ & TPB \\
Environmental knowledge & $11(+), 1(\mathrm{n} . \mathrm{s})$ & NAM/VBN \\
Income & $8(+), 2(-), 2(\mathrm{n} . \mathrm{s})$ & Socio-demographics \\
Environmental awareness & $6(+), 5(\mathrm{n} . \mathrm{s})$ & NAM/VBN \\
Perceived consumer effectiveness & $5(+), 1(\mathrm{n} . \mathrm{s})$ & TPB \\
Personal/moral norms & $5(+), 1(\mathrm{n} . \mathrm{s})$ & NAM/VBN \\
Trust & $5(+)$ & Psychographics \\
Religiosity & $6(+)$ & Socio-demographics \\
Family size & $3(+), 1(-), 1(\mathrm{n} . \mathrm{s})$ & Socio-demographics \\
Awareness of consequences & $4(+)$ & NAM/VBN \\
Environmental responsibility & $4(+)$ & NAM/VBN \\
Perceived benefits & $4(+)$ & Health Belief Model \\
Anticipated affect/emosions & $4(+), 1(-)$ & Theory of interpersonal behavior \\
Skepticism to environmental claims & $2(-), 2(\mathrm{n} . \mathrm{s})$ & Psychographics \\
Self-identity/image & $3(+), 1(\mathrm{n} . \mathrm{s})$ & Psychographics \\
*The table lists predictors that were present in at least 4 studies. &
\end{tabular}

*The table lists predictors that were present in at least 4 studies.

supports the idea that women are more oriented toward sustainable behaviors compared to men, evidence is not conclusive insofar, for instance, men show stronger inclinations toward organic purchasing compared to women (Mohamed, Chymis, and Shelaby 2012). According to Socialization Theory (Beutel and Marini 1995) women have a stronger ethic to care and are more concerned, as differences between genders can be attributed to what is expected from each of them based on the cultural context. This theory can explain the higher inclination of MENA women toward green purchase insofar, in predominantly male-empowered societies, women are deeply involved in taking care of children and family members. Further, women play an important role in the household level compared to men (Mobrezi and Khoshtinat 2016) and such role identity positions them as the main target group for certain SCBs such as household waste management, source separation and recycling (Babaei et al. 2015). However, women should not be the only targets for sustainable markets, since men are often considered as the head of the households, and hence play an integral role in purchasing decisions. From a cultural lens, this sounds reasonable due to the fact that, on the one hand, not many women work so they are not financially independent and, on the other hand, there is still a predominant mentality where men sometimes decide what women should purchase when shopping (Mohamed, Chymis, and Shelaby 2012). These traditional household roles seem to be more dynamic in other developing countries where women are increasingly gaining higher incomes. In Malaysia, for example, Kusago and Barham (2001) find that women show higher financial power than men at the household level. Yet, consistently with the MENA findings, Abdullah Yusof and Duasa (2010) reveal that Malaysian women usually make final decisions regarding everyday household expenditures, while large household expenditures are still made by men. This provides a more nuanced view of the role of gender in sustainable decisions where the nature or amount of expenditure is also relevant.

A second demographic variable for which the MENA sample reaches inconclusive results is represented by age. While some argue that older generations are more likely to assume responsible behaviors (due to experience, wisdom, etc.), others suggest that young people have grown exposed to messages and public discourse focusing on sustainability-related issues, so that it is reasonable to expect them to show more attention to such issues in their daily behaviors. Twelve out of twenty studies analyzing age find no significant relationship with SCB while, of the eight that do so, four suggest that young people are keener toward SCB and four reach the opposite result. 
Of the twenty studies reporting the impact of education on consumers' sustainable intention and/or behavior, eight find a significant positive impact as to signal that individuals with higher educational levels show more favorable intentions toward sustainable behaviors. But the relationship is far from clear, as nine studies find no significant effect of education, and three studies find either mixed or negative effects. Interestingly, an Egypt-based study by Rice (2006) finds that education is significantly related to activist and public sphere SCB, while not related to private sphere SCB. The implication that the impact of education varies considerably across behaviors is consistent with literature on other developing countries, showing similar inconsistencies. In China, for example, Wu, Zhou, and Song (2016) found a positive link between education and citizens' persuasion behavior, but a negative link with consumption management behavior.

The pattern is partially clearer for income, as eight studies out of twelve support a positive impact of the latter on consumer sustainable intentions and/or behavior. Consumers with higher income levels are thought to show high green purchase intentions, and this may be due to their ability to afford the premium price that green products typically entail (Mohamed, Chymis, and Shelaby 2012; Mostafa 2016). Agreement is however not general, as Mourad and Serag Eldin Ahmed (2012), for instance, found a negative relationship between income and green brand preference. Morren and Grinstein (2016, p.102) argue that "people in countries with a high human development level also act more environmentally." Thus, they suggest that aspects of human development, such as better income, education, and health, can be relevant to environmental behaviors across borders.

Yet, compared to Franzen and Vogl (2013) conclusion that GEIA variables appeared to be relevant across countries, there is insufficient evidence indicating that these socio-demographic variables show consistent patterns across behaviors.

One aspect that emerges as peculiar of studies in the MENA region is the role played by religiosity, a factor that is often overlooked by mainstream research in other socio-cultural environments. Religiosity refers to the individuals' level of commitment to behave following God's rules (McDaniel and Burnett 1990), and seems to play an influential role behind virtuous behaviors, as all six studies in the sample focusing on it show a positive correlation. The emergence of religiosity as a MENA-relevant determinant sounds justifiable due to the context under investigation, which calls consumers to consider the consequences of their action on other species and the environment in general. Indeed, Mostafa (2016) argues that in a predominantly Islamic nation, consumers are expected to be willing to sacrifice to protect the environment, since religiosity reflects a fundamental belief system with many religious orders about respecting nature and the environment. The Holy Quran states, for example, that "...eat and drink, and do not waste. God does not love the wasteful” (Qur'an 7:31).

While arguably religiosity can influence the consumers conceptions toward sustainable behaviors in the region object of analysis, there is no universal agreement on whether such influence is moderating, indirect or direct. Results from the review support the moderating role of religiosity (Bhuian et al. 2018), while Abdelradi (2018) argues that religious beliefs play an indirect role on SCBs (i.e., food waste reduction) through influencing environmental awareness. This in coherent with the TPB logic where religion is considered as a background factor (Ajzen 1991). On the other hand, another stream of research supports the direct link between religiosity and pro-environmental intentions and behaviors (Rice 2006; Siyavooshi, Foroozanfar, and Sharifi 2019).

Religiosity is likely to be associated with SCB with reference to most religions, given the universality of the message about the responsibility of men toward the natural world (Bhuian et al. 2018). However, the relevance of religiosity as behavioral antecedent in MENA countries is not matched in different geographical and cultural contexts: this could be linked to the key role that religion has in the region, compared for instance to western countries which appear more secularized. Little is available in literature to investigate the role of religiosity in different cultural contexts, as most of the research on religiosity analyses differences in SCBs between religious and not religious people, while evidence on the moderating effect of religiosity adopting a cross-cultural lens 
in anecdotal. For instance (although focusing on ethical consumer behavior and not specifically on SCB), Schneider, Krieger, and Bayraktar (2011) compare Christian consumers from Germany and Muslim consumers from Turkey, finding that the latter exhibit a stronger connection between ethical consumer behavior and religiosity: Muslims "generally possess more intrinsic religiosity than Christians and reject unethical consumer behavior more than Christians" (Schneider, Krieger, and Bayraktar 2011, p. 328). Further, the authors suggest that this pattern is likely to be even more pronounced for Muslim countries that are not as western-orientated as Turkey (such as most of the MENA region).

Among (mainly psychographic) variables that are less frequently included in analyses as antecedents of SCB, some deserve to be mentioned; it is the case for instance of trust and incentives.

Trust is found to have a significant positive effect on sustainable consumer intention and/or behavior: if consumers believe in the credibility of a specific product/brand, they are far more likely to buy it. Thus, lack of consumer trust in green products acts as a barrier toward green purchase behavior in the MENA region. This result is comparable with other recent reviews that underlined the importance of trust in sustainability contexts (Joshi and Rahman 2015; Tripathi and Singh 2016). As regards incentives, Elmustapha, Hoppe, and Bressers (2018) claim that financial incentives are often used in government policies to persuade householders to invest in renewable energy technology. However, the findings indicate a non-significant correlation between financial incentives and consumer renewable energy adoption in Lebanon. This can be attributed to the difficulty of applying for financial subsidies due to the high number of qualifications required (Elmustapha, Hoppe, and Bressers 2018). On the contrary, Mattar et al. (2018) find a significant impact of incentives on the participation to recycling programs, where monetary incentives have approximately twice the effect compared to getting information about food waste and correct recycling activities. The role of incentives on motivation to adopt SCBs is indeed object of a debate, as there are theoretical frameworks such as Self Determination and
Cognitive Evaluation Theories (Deci and Ryan 1985; Ryan and Deci 2000) suggesting that individuals spurred by economic inducements to perform a specific behavior have their motivation hindered, and the so-called locus of causality shifting outwards. The consequence is that, once inducements are interrupted, consumers are more likely to abandon the virtuous behavior.

\section{Habits and past behavior}

A surprising result of the review is that, while most of MENA-based papers are rooted in traditional frameworks of the rationalistic stream, habits are relegated to a negligible role. Indeed, there is only scattered evidence about the role they play in determining SCB. One of the few examples is represented by an empirical investigation performed in the UAE, where water conservation habits are included in the TPB framework in order to segment the population as a pre-requisite for the implementation of behavioral change strategies (Ibrahim et al. 2018).

Few more studies focus on the other hand on the role played by past behaviors, though it is worth stressing how these and habits represent two highly correlated yet different constructs which are not synonyms and should not be treated as such: the frequent repetition of a behavior represents a necessary yet not sufficient element for the development of a genuine habit (Verplanken and Aarts 1999). For instance, Pakpour et al. (2014) find that past behavior significantly predicts householders waste behaviors in Iran, while according to Düştegör et al. (2018) consumers' past experience in using energy-saving appliances in Saudi Arabia positively increases their willingness to buy green energy. Further, in a study performed on a sample of Saudi Arabia consumers, Abdul-Muhmin (2007) finds that past environmentally friendly behavior is positively related to perceived psychological consequences, while not directly related to willingness to be environmentally friendly so that it only has an indirect effect on behaviors.

In contrast with the scant evidence available in MENA-based literature, in other socio-cultural contexts the role of habits in shaping SCB has been object of a wealthy stream of research. An 
overwhelming majority of such evidence is focused on western countries. For instance, if we focus on the domain of sustainable mobility, Hoffmann et al. (2017) performed a meta-analysis on the determinants of modal choice: of the forty-three studies retained for the analysis (all from developed countries, thirty-six of which European), eleven investigated the role exerted by habits, confirming the strong influence of the latter in shaping behavioral patterns.

If we shift the focus to other developing countries, Issock, Roberts-Lombard, and Mpinganjira (2020) found that habits have a direct effect on recycling behaviors of households in South Africa, while Lanzini, Pinheiro, and Jara (2018) performed an empirical investigation on the determinants of sustainable mobility in the state of Santa Catarina (Brazil), finding that habits outperform TPB variables as behavioral antecedents. Although most studies are consistent with the assumption that habits represent crucial behavioral antecedents in the domain of sustainability, there is also some evidence supporting an alternative view. It is the case for instance of the work of Nguyen, Zhu, and Le (2015) on waste separation in Vietnam, where the role of habits is found to be secondary.

\section{Planned behavior variables}

TPB is arguably the most popular framework adopted in literature to investigate SCB. Although under scrutiny for an over-simplification of its original formulation and the persistent observation of the attitude-behavior gap (Liu, Oosterveer, and Spaargaren 2016), TPB has been extensively adopted to investigate a broad range of behavioral domains, including those closely related to sustainability. Although "the TPB is broadly predictive of behavioral intent within and across cultures" (Mancha and Yoder 2015, p. 147)" more insights on how the cultural context affects the salience of the different TPB constructs (attitudes, subjective norms and $\mathrm{PBC}$ ) is needed. Minton et al. (2018), for instance, performed a cross-cultural exploration of the role played by TPB constructs in shaping behavioral patterns. They argue that some features of the country of origin (e.g., the level of pragmatism) affect the salience of subjective norms and attitudes: " $[t]$ he cultural origin of a consumer is hypothesized as an antecedent to attitudes, which precedes sustainable behaviors, and the pragmatism in a national culture is hypothesized as moderating sustainable behavior intentions" (Minton et al. 2018, p. 401).

Countries in the MENA region make no exception insofar TPB confirms to be widely adopted in investigating sustainable behaviors. Although the theory itself is not always explicitly mentioned, its components are analyzed by many studies as antecedents of sustainable behaviors (sometimes jointly, sometimes as stand-alone).

Consumers' intention has been investigated intensively in the reviewed papers either as a dependent variable or as a predictor of behavior, and thirteen studies found a significant link between consumers' intention and behavior. This goes in line with the TPB logic, where intention is the best predictor of behavior, and planning is the main carrier of intentions. Further, many studies try to identify the predictors of intentions toward sustainable behavior. Notwithstanding the variability of behaviors analyzed, the main antecedents of individuals sustainable intentions include attitudes, subjective norms and PBC (behavioral antecedents in the original TPB framework) but also trust, knowledge, environmental concern as well as demographics and contextual factors.

Attitude emerges as the single most studied variable, being investigated in thirty-two papers. There is broad consensus on the direct and significant impact of consumers' attitudes on their sustainable intentions and behaviors: indeed, twenty-eight papers find a significant and positive impact. In line with Joshi and Rahman (2015), some scholars claim that there are other factors that affect and moderate the strength of the attitude-behavior relationship, either positively like in the case of green advertising (Attia 2014) or negatively like in the case of green skepticism (Zarei and Maleki 2018).

Eighteen studies examine the influence of subjective/social norms and social influence on sustainable intention and/or behavior. Although in twelve studies social influence and norms are found to have a positive correlation with sustainable consumer decisions, compared to attitudes the results appear to be less straightforward as a significant number of studies find no relevant 
correlation with actual behaviors. This is consistent with the claim that subjective norms are the only variable in the TPB which significantly depends on economic development (Liobikiene, Mandravickaite, and Bernatonienè 2016): Minbashrazgah, Maleki, and Torabi (2017) conclude that in contrast to European countries, in some developing countries subjective norms do not affect significantly green purchase intentions.

$\mathrm{PBC} / \mathrm{PCE}$ represents the third antecedent of behavioral intentions (and, in turn, of actual behaviors) according to the original TPB framework. Of the twenty studies investigating such predictors, seventeen found a positive correlation with SCB, while in three cases the correlation appears to be not significant. This result underlines the important role of maintaining control over conditional factors that might support or hinder sustainable behaviors. Indeed, it is often difficult for individuals to walk the talk with respect to sustainable behaviors, if these are (perceived as) demanding from an economic or contextual standpoint. For instance, it has been found that consumers face the difficulty of finding ecological products on store shelves, in addition to their higher price (Nejati, Salamzadeh, and Salamzadeh 2011). Further, in the food waste context, Aktas et al. (2018) found a negative (positive) relationship between the difficulty to store food and intentions (behavior) to reduce food waste. Or, in the domain of recycling, Babaei et al. (2015) found that not having easy access to the recycling bins, lack of awareness toward recycling programs, lack of proper municipality services and lack of financial incentives (rewards and penalties) represent the main hindering factors preventing individuals to act responsively.

Interestingly, while TPB holds its validity across cultural contexts, the relative salience of its constructs may vary according to the country where investigations are performed. Two main differences emerge.

First, there is a difference between developed and developing countries as far as $\mathrm{PBC}$ is concerned. Indeed, PBC is a key-predictor of SCB especially in MENA countries and other developing economies (Chan and Lau 2002), while in western countries (although still a relevant predictor) the role played is not as crucial. This is likely due to the lack of both resources and opportunities characterizing developing countries, where the availability of sustainable options might be limited making difficult even for responsible consumers to act according to their sustainability-oriented beliefs. This is not only the case of MENA countries as showed by our review. De Freitas, van Eeden, and Christie (2020) performed an investigation on SCB in South Africa adopting (an extended version of) the TPB framework, finding that PBC showed the strongest impact on behavioral intentions. Similarly, Yang, Li, and Zhang (2018) found that PBC was the stronger predictor of sustainable consumption intention on a sample of Chinese consumers, in the domain of online shopping.

Second, there are culture-specific differences that even differentiate MENA from other developing countries, like in the case of subjective norms. While their role in MENA countries appears to be secondary, individuals from Confucian cultures in the Far East display a much stronger propensity to comply with the norms of their relevant ones (Chan and Lau 2002), as the image they irradiate within their social circles assumes a paramount importance. Lee (1991) labels this collectivistic feature of Confucian societies "group conformity". Although particularly evident in Confucian societies, there is also evidence in literature from other developing countries that, compared to the MENA region, subjective norms and social screening seemingly play a more prominent role: it is the case for instance of South Africa (Strydom 2018) or Brazil (Echegaray and Hansstein 2017).

\section{Altruistic and environmental variables}

Environmental (or, more broadly, altruistic) values also emerge as a key driver of SCB in the MENA region. Interestingly, while environmental concern and knowledge/awareness have been investigated by a large number of studies (which indicate, especially in the case of concern, high correlations with SCB), constructs referring to structured normative models such as NAM or VBN (e.g., personal norms, awareness of consequences and responsibility) are considered less frequently. 
Environmental concern ranks among the most studied variables, with sixteen out of seventeen studies reporting a significant positive and direct impact of environmental concern on sustainable intentions and/or behaviors. Other studies focus on an indirect relationship between environmental concern and sustainable behaviors. For instance, Vazifehdoust et al. (2013) tested a more complex (indirect) relationship between the two constructs, where environmental concern has a positive effect on consumer's attitudes toward green products, which in turn have an influence on intentions and then behavior. Conversely, Esmaeilpour and Bahmiary (2017) report that environmental attitude of consumers has a significant positive impact on their environmental concerns, which in turn have a positive influence on the decision to purchase a green product. Regardless of the direct/indirect nature of the relationship, the relevance of environmental concern in shaping SCB is also confirmed by nonMENA literature, and supported by a wide range of studies in both developed and developing countries (Prakash and Pathak 2017; Tripathi and Singh 2016; Yadav and Pathak 2016). However, the conclusion of Franzen and Vogl (2013, p. 1006) that, "[...] more wealthy nations tend to have higher environmental concern" can neither be proved nor disproved given the available results in the MENA region. It could be speculated that constructs such as PBC can mediate the effect of environmental concern on actual behaviors, especially in case of SCBs that are difficult to implement either for the lack of alternatives or for the costs they entail. This is seemingly a situation affecting most developing countries: for instance, Lanzini, Pinheiro, and Jara (2018) found that environmental variables are a crucial predictor of the intention to adopt sustainable mobility behaviors in Brazil, but much less so with reference to actual behaviors.

Environmental knowledge (and the closely related concept of awareness) represent the constructs that, besides environmental concern, received most attention in the MENA sample, as they have been investigated by a relevant number of studies, with most articles (seventeen out of twenty-three) suggesting a positive influence on SCBs. Some studies suggest a more complex relationship between environmental knowledge and behavior, with the former having both a direct and an indirect impact on the latter, through attitude (Saleki, Seyedeh, and Rahimi 2012). Further, Abdelradi (2018) finds that, among other factors, environmental awareness is increased by having more knowledge about the food waste problem. Other studies, however, find a non-significant association between environmental knowledge and attitudes toward green purchase (Vazifehdoust et al. 2013). A possible explanation could be the shift from a specific context (e.g., buying organic food) to a generic one (e.g., green purchase), which is consistent with Morren and Grinstein's claim that differences across countries can also be attributable to some methodological aspects where "studies with a general topic have higher effect sizes that those studies who focus on specific behaviors" (Morren and Grinstein 2016, p.102). Overall, the above findings suggest that environmental knowledge and awareness have positive and significant influence on consumer sustainable intention and behavior in the MENA region. Yet, it is still not clear if the distinction between abstract knowledge (awareness of environmental problems, causes, solutions, and so on) and concrete knowledge (awareness of behavioral and practical guidelines) (Schahn and Holzer 1990) could influence SCBs differently.

As previously stated, constructs referring to structured normative models such as NAM or VBN are considered less frequently by studies in the dataset yet display a clearly positive correlation with sustainable behaviors. Interestingly, the normative models that have originally been developed for pro-social and pro-environmental behaviors seem to be far less applied compared to the TPB in general. Steg and Vlek (2009) argue that normative models might be more efficient with low cost behaviors, while TPB works better with high cost behaviors. This conclusion is also evident in Sarkis's study (2017): while VBN is preferred for voluntary green power behaviors related to the public good, TPB is much more suitable for energy efficiency behaviors related to the self. This supports the growing inclination of scholars toward the integration of different models (e.g., Choi, Jang, and Kandampully 2015; Elhoushy 2020; Han 2014; 
Kiatkawsin and Han 2017; Yadav and Pathak 2017); however, further comparisons are needed to reveal which theoretical frameworks are most effective across behaviors.

If we focus on NAM constructs, personal norms are found to have a positive relationship with SCB in five of the six analyzed papers. For instance, they show a considerable significant impact on householders' intention to use renewable energy sources (Rezaei and Ghofranfarid 2018); similarly, adding moral norms to the TPB model significantly contributes to the explanation of organic food purchase intentions (Yazdanpanah and Forouzani 2015), consistently with a growing strand of studies across countries (e.g., de Freitas et al., 2020; Graham-Rowe, Jessop, and Sparks 2015; Han and Hansen 2012). Indeed, personal norms do not influence behavior directly, as they are instead correlated to intentions (Klöckner 2013; Rivis, Sheeran, and Armitage 2009). Further, based on the deontic justice theory, Ibrahim and Al-Ajlouni (2018) support the significant positive impact of moral obligation, moral accountability and moral outrage on green purchase intention, which positions green consumption as a moral issue. Notably, norms do not emerge as significant predictors of adopting solar water heaters in the household in the study of Elmustapha, Hoppe, and Bressers (2018): this indicates that consumer decisions (not) to adopt sustainable technologies rely mainly on technology-related attributes rather than on social and moral norms.

As regards the role of awareness of consequences on $\mathrm{SCB}$, it is worth stressing how these can be both immediate and future (or, in other words, awareness can pertain to both short-term and long-term consequences of a given activity). Rice (2006) found a significant impact of anticipated negative consequences (i.e., polluting the environment, causing diseases for children, noise) on pro-environmental behaviors in Egypt, while Dezdar (2017) claims that the consideration of future consequences is positively associated with the intention to use green IT among Iranian students. Evidence from other developing countries such as South Africa (Taljaard, Sonnenberg, and Jacobs 2018) also supports the positive link between awareness of environmental problems and green intentions. Furthermore, the seriousness of consequences in the eyes of individuals emerges as a relevant issue, capable of affecting behavioral patterns. For instance, Dagher and Itani (2014) found a positive relationship between the perceived seriousness of environmental problems and green purchasing behaviors of Lebanese consumers, with Moon, Mohel, and Farooq (2020) reaching consistent results in Pakistan, where perceived seriousness of environmental problems had significant positive influence on green attitude. Further, Abdul-Muhmin (2007) elaborates on the distinction between local and global environment, in the sense that perceived seriousness of environmental problems in the local environment is more tangible and based on direct personal experience. As a consequence, perceived threats to the local environment will have a relatively larger effect on environmental concern (thus, on behaviors) than perceived threat to the global environment: this makes locally framed messages as potentially more effective in these societies.

The third NAM construct, ascription of responsibility, is also confirmed to exert a positive influence on SCB. For instance, Dagher and Itani (2014) found a positive relationship between Lebanese consumers' perception of environmental responsibility and their green purchasing behaviors, while Minbashrazgah, Maleki, and Torabi (2017) found that perceived environmental responsibility exerts a positive impact on green chicken purchase intention among Iranian consumers. However, evidence also suggests that in many occasions individuals believe that environmental preservation is (mainly) responsibility of others, a broad category including not only other citizens, but also (and primarily) actors such as companies or public authorities (Kalantari and Asadi 2010; Yaghi and Alibeli 2017). This is comparable with results from Pakistan (Moon, Mohel, and Farooq 2020), where perceived environmental responsibility had a non-significant influence on green attitude: if this is the case, individuals might be unwilling to pay a premium or to make a contribution knowing that someone else will do it. In a similar vein, Rice (2006, p. 376) concludes that "if individuals are environmentally concerned but are convinced that only 
business or the government can provide effective solutions, they might not engage in much proenvironmental behavior". This finding corresponds with the claim that individuals perceive large-scale problems such as climate change and environmental degradation as global issues that require governmental, rather than individual, solutions (Grinstein and Riefler 2015).

In conclusion, the review of literature in MENA countries confirms the importance of altruistic and environmental variables. Yet, from a cultural lens, current evidence suggests that differences can exist between (and within) countries regarding altruistic and moral obligations, even in areas sharing similar cultural backgrounds. This is the case for both developing and developed countries: Arvola et al. (2008), for instance, found that the relative importance of norms with reference to organic food purchase intentions varied between three western countries such as Finland, the UK and Italy. These differences can be attributable to some cultural dimensions, such as the so-called power distance characterizing different countries: most of the MENA countries score high on such element ${ }^{4}$, which could explain the observed tendency to ascribe responsibility of global problems to governments.

\section{Conclusions and future steps}

Countries in the MENA region are expected to experience an economic growth over the next years and decades which is likely to increase the footprint of communities living in the area, given more affluent production and consumption patterns. Gaining better understandings on the motives underpinning SCB in the region hence assumes a strategic relevance, as a prerequisite for the effective implementation of environmental policies and institutional actions from local as well as international policymakers. Indeed, while most studies and reviews on the topic are based in western countries, it is plausible to infer that different social, economic, and cultural contexts follow (at least partially) different patterns. The review collects and systematizes existing evidence on the topic: most of MENA-based papers are rooted in traditional frameworks of the rationalistic stream, and show environmental values as a key driver of sustainable behaviors, while habits and socio-demographics are relegated to an ancillary role. Of particular interest are some aspects emerging as peculiar of the region, such as the role of religiosity and (to a lesser extent) of gender. Moreover, while traditional frameworks are confirmed to be effective tools for the analysis of SCBs, the relative salience of their constructs might be different in MENA countries compared to other developed or even developing countries, such as in the case of subjective norms.

As regards such frameworks, however, it is worth stressing how MENA-based research rarely considers theories in their original, complete formulations (that is, analyzing all the variables of the original model). On the contrary, papers often focus on some of such variables only, either alone or in combination with predictors rooted in different theoretical frameworks. This has both positive and negative consequences. While integrating on the one hand different perspectives, it hinders on the other hand an effective comparison of results across studies: since every single investigation focuses on a different set of SCB predictors, it is difficult to identify a common pattern, capable of making sense of an array of empirical results.

Future research should be fine-tuned from a methodological as well as from a theoretical standpoint, as to provide policy makers and all interested parties with a more reliable overview on the antecedents of SCB in the MENA region. As regards methodological aspects, limitations that should be addressed refer to i) the low reliability of self-reported behaviors, ii) the fact that most studies are based on either convenience samples or on students (which might not be highly representative of the overall population), and iii) the fact that most of the studies focus on a limited subset of SCBs, and consider mostly the environmental side while overlooking the social dimension. Future research should hence broaden the scope to behavioral domains that are bound to increase in relevance in years to come (such as private urban mobility) or that are of particular interest given the specificities of the MENA region (such as water saving activities). Further, it would be important to give equal dignity to all 
different perspectives representing the pillars of sustainability.

As regards the theoretical perspective, while most investigations adopt a static approach focusing on responsible behaviors in a specific moment in time (that is, stemming from a static decision rather than as a dynamic, unfolding process that evolves over time), future research should consider at once the further stages of consumer decision: that is, the outcomes of SCB and continuance over time. Further, the reviewed literature revealed that scholars delve basically on the rational/cognitive family of theories, while a peculiar aspect emerging from the review reflects the absence of habits as a relevant behavioral predictor; future studies should integrate existing evidence with analyses that consider both rational/aware behavioral antecedents, and automaticity-related ones. Most importantly, research should avoid the fragmentation that affects most of current investigations, with the adoption of a plethora of heterogeneous variables often lacking an overarching and structured model linking them together in a coherent theory.

Building on the review performed on the determinants of SCB in the MENA region, we wish to conclude our work proposing an interpretive framework, whose empirical testing we leave to future studies (Figure 1). The framework, which is generalizable and testable across a wide range of SCBs, integrates predictors from

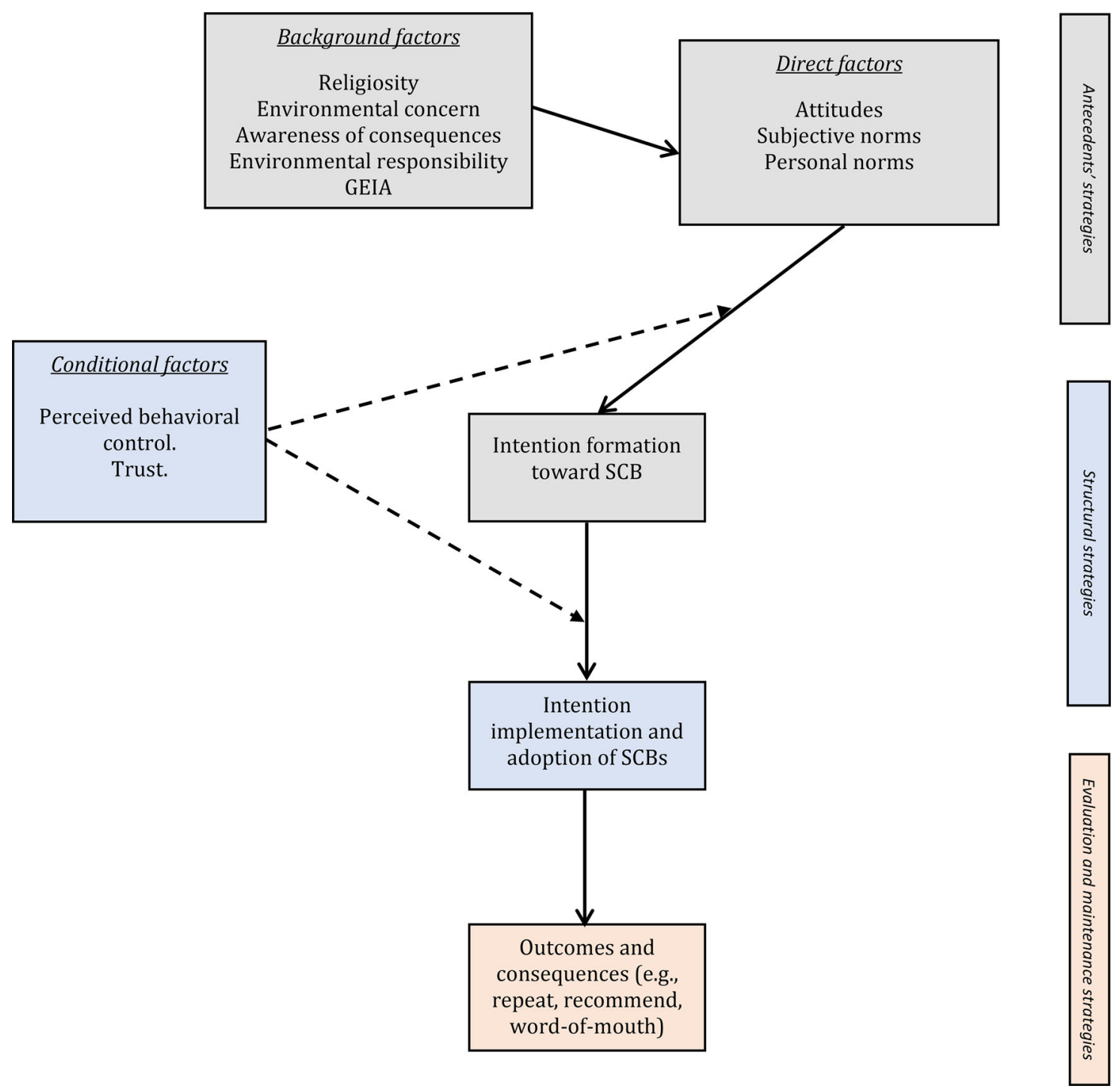

Figure 1. MENA-based conceptual framework for the key determinants of sustainable consumer behaviors. Note: Dotted arrows represent potential moderating effects. 
different mainstream models, considering at once MENA specificities and cultural factors.

The proposed framework suggests three overlapping strategies for communicating SCB to consumers: antecedents' strategies, structural strategies, and evaluation/maintenance strategies. The first focuses on motivational, informational, and educational efforts to activate the key direct and indirect predictors of individuals' intentions toward SCB. Based on the obtained results, it is argued that attitudes, subjective norms, and personal norms play an important role in forming behavioral intentions, which, in turn, lead to the adoption of SCB. Further, another set of factors emerges as relevant to behavioral intention: specific socio-demographic variables (e.g., religiosity), environmental knowledge, awareness of consequences and ascription of responsibility. It has been argued that these variables play an indirect role in shaping intentions and behaviors (Ajzen 1991; Schwartz and Howard 1981; Stern et al. 1999).

Further, MENA-based results highlighted several barriers, such as availability, premium prices and lack of trust. The second strategy focuses on structural aspects, aiming at the removal of barriers and at facilitating SCB. Thereby, both PBC and trust are introduced as conditional variables: that is, attitudes, subjective norms and personal norms are expected to lead to intentions to the extent that individuals hold high $\mathrm{PBC}$ and trust the targeted SCB. In addition, trust and PBC also moderate the link between intention and adoption of SCB.

Lastly, the evaluation and maintenance strategy take the conversation forward by focusing on the outcomes and consequences of adopting SCB. Mainstream studies often focus on the antecedents of intentions while sometimes marginalizing behavioral outcomes and, especially, subsequent actions. It is argued that after adopting SCB, individuals will evaluate their perceived performance, which in turn may lead to satisfaction or dissatisfaction, and confirmation or disconfirmation of their beliefs: in this context, perceived performance, confirmation, and satisfaction are key determinants for future behaviors (Oliver 1980). Thus, policy makers, marketers, and researchers need to focus on the post-adoption outcomes to better understand subsequent behavioral patterns (i.e., repeat, recommend, and word-of-mouth).

\section{Notes}

1. The interchangeable use of PBC, Perceived Consumer Effectiveness (PCE) and self-efficacy is frequent in the current literature.

2. The complete string can be retrieved from authors.

3. Algeria, Bahrain, Egypt, Iran, Iraq, Jordan, Kuwait, Lebanon, Libya, Morocco, Oman, Qatar, Saudi Arabia, State of Palestine, Syrian Arab Republic, Tunisia, United Arab Emirates, and Yemen.

4. Official Website of Hofstede's cultural dimensions across countries: Accessed 25th May 2020: https://www.hofstede-insights.com/product/ compare-countries/

5. Outcome variable is in italics if it is about intentions rather than behaviors, and bold if it is about both intention and behavior.

6. Predictors are in in italics if they predict intentions rather than behavior, and bold if they predict both intention and behavior.

\section{Declarations of interest}

none

\section{Funding}

This research did not receive any specific grant from funding agencies in the public, commercial, or not-forprofit sectors.

\section{ORCID}

Sayed Elhoushy (D) http://orcid.org/0000-0003-3434-8171

\section{References}

Aarts, H., and A. Dijksterhuis. 2000. Habits as knowledge structures: Automaticity in goal-directed behavior. Journal of Personality and Social Psychology 78 (1):53-63. doi: 10.1037//0022-3514.78.1.53.

Abdelradi, F. 2018. Food waste behaviour at the household level: A conceptual framework. Waste Management (New York, N.Y.) 71:485-93. doi: 10.1016/j.wasman.2017.10.001.

Abdullah Yusof, S., and J. Duasa. 2010. Household DecisionMaking and Expenditure Patterns of Married Men and Women in Malaysia. Journal of Family and Economic Issues 31 (3):371-81. doi: 10.1007/s10834-010-9200-9.

Abdul-Muhmin. A. G. 2007. Explaining consumers' willingness to be environmentally friendly. International Journal of Consumer Studies 31 (3):237-47.

Abrahamse, W. 2019. Encouraging Pro-environmental Behavior: What Works, what Doesn't, and why. Cambridge, MA: Academic Press. 
Ajzen, I. 1985. From intentions to actions: A theory of planned behavior. In Action control, 11-39. Berlin, Heidelberg: Springer.

Ajzen, I. 1991. The theory of planned behavior. Organizational Behavior and Human Decision Processes 50 (2):179-211. doi: 10.1016/0749-5978(91)90020-T.

Akermi, A., and F. Smaoui. 2016. The Effect of Cultural Values And Religiosity on Socially Responsible Consumption. Proceedings of the Marketing Spring Colloquy (MSC), 6, 22-34.

Akroush, M. N., M. I. Zuriekat, H. I. Al Jabali, and N. A. Asfour. 2019. Determinants of purchasing intentions of energy-efficient products: The roles of energy awareness and perceived benefits. International Journal of Energy Sector Management 13 (1):128-48. doi: 10.1108/IJESM05-2018-0009.

Aktas, E., H. Sahin, Z. Topaloglu, A. Oledinma, A. K. S. Huda, Z. Irani, A. M. Sharif, T. van't Wout, and M. Kamrava. 2018. A consumer behavioral approach to food waste. Journal of Enterprise Information Management 31 (5):658-73. doi: 10.1108/JEIM-03-2018-0051.

Almossawi, M. 2014. Promoting green purchase behavior to the youth (case of Bahrain). British Journal of Marketing Studies 2 (5):1-16.

Al-Otoum, F. J., and R. S. Nimri. 2015. Antecedents of Environmental Buying Behavior: Case of the Jordanian Market. International Journal of Business and Management 10 (9):240-50. doi: 10.5539/ijbm.v10n9p240.

Alsmadi, S. 2007. Green marketing and the concern over the environment: Measuring environmental consciousness of Jordanian consumers. Journal of Promotion Management 13 (3-4):339-61. doi: 10.1080/10496490802306905.

Al-Thawadi, S. 2018. Public perception of algal consumption as an alternative food in the Kingdom of Bahrain. Arab Journal of Basic and Applied Sciences 25 (1):1-12. doi: 10.1080/25765299.2018.1449344.

Arvola, A.,. M. Vassallo, M. Dean, P. Lampila, A. Saba, L. Lähteenmäki, and R. Shepherd. 2008. Predicting intentions to purchase organic food: The role of affective and moral attitudes in the Theory of Planned Behaviour. Appetite 50 (2-3):443-54. doi: 10.1016/j.appet.2007.09.010.

Asif, M., W. Xuhui, A. Nasiri, and S. Ayyub. 2018. Determinant factors influencing organic food purchase intention and the moderating role of awareness: A comparative analysis. Food Quality and Preference 63:144-50. doi: 10.1016/j.foodqual.2017.08.006.

Attia, S. T. 2014. The Effect of Green Advertising as a Moderator on Green Purchase Attitude-Green Purchase Intentions Relationship. The Case of Young Egyptian Consumers. Journal of IMS Group 11 (1):01-15.

Attia, S., and M. Farrag. 2017. The Effect of Egyptian Consumer Values \& Lifestyles on Green Purchase Behavior. Journal of Marketing Development and Competitiveness 11 (4):49-65.

Azar, E., and H. Al Ansari. 2017. Framework to investigate energy conservation motivation and actions of building occupants: The case of a green campus in Abu Dhabi,
UAE. Applied Energy 190:563-73. doi: 10.1016/j.apenergy. 2016.12.128.

Babaei, A. A., N. Alavi, G. Goudarzi, P. Teymouri, K. Ahmadi, and M. Rafiee. 2015. Household recycling knowledge, attitudes and practices towards solid waste management. Resources, Conservation and Recycling 102: 94-100. doi: 10.1016/j.resconrec.2015.06.014.

Bagher, A. N., F. Salati, and M. Ghaffari. 2018. Factors Affecting Intention to Purchase Organic Food Products Among Iranian Consumers. Academy of Marketing Studies Journal 22 (3). Accessed at: https://www.abacademies.org/ articles/factors-affecting-intention-to-purchase-organic-foodproducts-among-iranian-consumers-7570.html.

Bamberg, S., and G. Möser. 2007. Twenty years after Hines, Hungerford, and Tomera: A new meta-analysis of psycho-social determinants of pro-environmental behaviour. Journal of Environmental Psychology 27 (1):14-25. doi: 10.1016/j.jenvp.2006.12.002.

Baqer, S. M. 2012. True green consumers: An investigation of consumers' genuine willingness to share environmental responsibility. Global Journal of Business Research 6 (3): 37-48. 2012

Belz, F.-M., and K. Peattie. 2009. Sustainability marketing: A global perspective. Chichester: Wiley.

Beutel, A. M., and M. M. Marini. 1995. Gender and values. American Sociological Review 60 (3):436-48. doi: 10.2307/ 2096423.

Bhuian, S. N., S. K. Sharma, I. Butt, and Z. U. Ahmed. 2018. Antecedents and pro-environmental consumer behavior (PECB): The moderating role of religiosity. Journal of Consumer Marketing 35 (3):287-99. doi: 10. 1108/JCM-02-2017-2076.

Carrington, M., A. Chatzidakis, H. Goworek, and D. Shaw. 2020. Consumption Ethics: A Review and Analysis of Future Directions for Interdisciplinary Research. Journal of Business Ethics :1-24.

Caruana, R., and A. Chatzidakis. 2014. Consumer Social Responsibility (CnSR): Toward a Multi-Level, MultiAgent Conceptualization of the "Other CSR. Journal of Business Ethics 121 (4):577-92. doi: 10.1007/s10551-0131739-6.

Chan, R. Y. K., and L. B. Y. Lau. 2002. Explaining Green Purchasing Behavior: A cross-cultural study on American and Chinese consumers. Journal of International Consumer Marketing 14 (2-3):9-40. doi: 10.1300/ J046v14n02_02.

Charbaji, A., and J. Hayek. 2003. Motives for Buying Organic Food in Lebanon. Journal of Environmental Sciences 26 (2):222-3.

Chatzidakis, A., D. Shaw, and M. Allen. 2018. A psychosocial approach to consumer ethics. Journal of Consumer Culture 0 (0):146954051877381-23. doi: 10.1177/ 1469540518773815.

Choi, H., J. Jang, and J. Kandampully. 2015. Application of the extended VBN theory to understand consumers' decisions about green hotels. International Journal of 
Hospitality Management 51:87-95. doi: 10.1016/j.ijhm. 2015.08.004.

Dagher, G. K., and O. Itani. 2014. Factors influencing green purchasing behavior: Empirical evidence from the Lebanese consumers. Journal of Consumer Behaviour 13 (3):188-95. doi: 10.1002/cb.1482.

Dagher, G., O. Itani, and A. N. Kassar. 2015. The impact of environment concern and attitude on green purchasing behavior: Gender as the moderator. Contemporary Management Research 11 (2):179-206. doi: 10.7903/cmr. 13625.

De Freitas, D., T. S. van Eeden, and L. Christie. 2020. A psychographic framework for determining South African consumers' green hotel decision formation: Augmenting the Theory of Planned Behaviour. Journal of Consumer Sciences 48: 1-18.

Deci, E., and R. Ryan. 1985. Intrinsic motivation and selfdetermination in human behavior: Berlin, Germany: Springer Science \& Business Media.

Dehghanan, H., and G. Bakhshandeh. 2014. The Impact of Green Perceived Value and Green Perceived Risk on Green Purchase Behavior of Iranian Consumers. International Journal of Management and Humanity Sciences 3 (2):1349-57.

Dezdar, S. 2017. Green information technology adoption: Influencing factors and extension of theory of planned behavior. Social Responsibility Journal 13 (2):292-306. doi: 10.1108/SRJ-05-2016-0064.

Diamantopoulos, A., B. B. Schlegelmilch, R. R. Sinkovics, and G. M. Bohlen. 2003. Can socio-demographics still play a role in profiling green consumers? A review of the evidence and an empirical investigation. Journal of Business Research 56 (6):465-80. https://doi.org/10.1016/S01482963. (01)00241-7 doi: 10.1016/S0148-2963(01)00241-7.

Douglas, S. P., and C. S. Craig. 1997. The changing dynamic of consumer behavior: Implications for cross-cultural research. International Journal of Research in Marketing 14 (4):379-95. doi: 10.1016/S0167-8116(97)00026-8.

Düştegör, D.,. N. Sultana, N. Felemban, and D. Al Qahtani. 2018. A smarter electricity grid for the Eastern Province of Saudi Arabia: Perceptions and policy implications. Utilities Policy 50:26-39. doi: 10.1016/j.jup.2017.09.009.

Echegaray, F., and F. V. Hansstein. 2017. Assessing the intention-behavior gap in electronic waste recycling: The case of Brazil. Journal of Cleaner Production 142:180-90. doi: 10.1016/j.jclepro.2016.05.064.

Elhoushy, S. 2020. Consumers' sustainable food choices: Antecedents and motivational imbalance. International Journal of Hospitality Management 89:102554. doi: 10. 1016/j.ijhm.2020.102554.

Elmustapha, H., T. Hoppe, and H. Bressers. 2018. Consumer renewable energy technology adoption decision-making; comparing models on perceived attributes and attitudinal constructs in the case of solar water heaters in Lebanon. Journal of Cleaner Production 172: 347-57. doi: 10.1016/j.jclepro.2017.10.131.
Esmaeilpour, M., and E. Bahmiary. 2017. Investigating the impact of environmental attitude on the decision to purchase a green product with the mediating role of environmental concern and care for green products. Management \& Marketing 12 (2):297-315. doi: 10.1515/ mmcks-2017-0018.

Fishbein, M., and I. Ajzen. 1975. Belief, attitude, intention and behavior: An introduction to theory and research. Reading, Mass.: Addison Wessley.

Franzen, A., and D. Vogl. 2013. Two decades of measuring environmental attitudes: A comparative analysis of 33 countries. Global Environmental Change 23 (5):1001-8. doi: 10.1016/j.gloenvcha.2013.03.009.

Grace, D., and I. Omar. 2012. The influence of environmental attitude, environmental concern and social influence on green purchasing behavior. Review of Business Research 12 (2):104-11.

Graham-Rowe, E., D. C. Jessop, and P. Sparks. 2015. Predicting household food waste reduction using an extended theory of planned behaviour. Resources, Conservation and Recycling 101:194-202. doi: 10.1016/j. resconrec.2015.05.020.

Grinstein, A., and P. Riefler. 2015. Citizens of the (green) world? Cosmopolitan orientation and sustainability. Journal of International Business Studies 46 (6):694-714. doi: 10.1057/jibs.2015.1.

Haghjou, M., B. Hayati, E. Pishbahar, R. Mohammadrezaei, and G. Dashti. 2013. Factors affecting consumers' potential willingness to pay for organic food products in Iran: Case study of Tabriz. Journal of Agricultural Science and Technology 15 (2):191-202.

Han, H. 2014. The norm activation model and theorybroadening: Individuals' decision-making on environmentally-responsible convention attendance. Journal of Environmental Psychology 40:462-71. doi: 10.1016/j.jenvp. 2014.10.006.

Han, Y., and H. Hansen. 2012. Determinants of Sustainable Food Consumption: A Meta-Analysis Using a Traditional and a Structura Equation Modelling Approach. International Journal of Psychological Studies 4 (1):22. doi: 10.5539/ijps.v4n1p22.

Hoffmann, C., C. Abraham, M. P. White, S. Ball, and S. M. Skippon. 2017. What cognitive mechanisms predict travel mode choice? A systematic review with meta-analysis. Transport Reviews 37 (5):631-52. doi: 10.1080/01441647. 2017.1285819.

Ibrahim, H., and M. M. Q. Al-Ajlouni. 2018. Sustainable consumption: Insights from the protection motivation (PMT), deontic justice (DJT) and construal level (CLT) theories. Management Decision 56 (3):610-33. [Mismatch] doi: 10.1108/MD-05-2016-0323.

Ibrahim, A., K. Knox, S. Rundle-Thiele, and D. Arli. 2018. Segmenting a Water Use Market: Theory of Interpersonal Behavior Insights. Social Marketing Quarterly 24 (1):3-17. doi: 10.1177/1524500417741277.

Issa, N. S. C., and S. D. Al Abbar. 2015. Sustainability in the Middle East: Achievements and challenges. 
International Journal of Sustainable Building Technology and Urban Development 6 (1):34-8. doi: 10.1080/ 2093761X.2015.1006709.

Issock, P. B. I., M. Roberts-Lombard, and M. Mpinganjira. 2020. Understanding household waste separation in South Africa. Management of Environmental Quality: An International Journal 31 (3):530-47. doi: 10.1108/MEQ08-2019-0181.

Joshi, Y., and Z. Rahman. 2015. Factors Affecting Green Purchase Behavior and Future Research Directions. International Strategic Management Review 3 (1-2): 128-43. doi: 10.1016/j.ism.2015.04.001.

Kalantari, K., and A. Asadi. 2010. Designing a structural model for explaining environmental attitude and behavior of urban residents (Case of Tehran). International Journal of Environmental Research 4 (2):309-20.

Khan, N., and P. Trivedi. 2015. Gender Differences and Sustainable Consumption Behavior. British Journal of Marketing Studies 3 (3):29-35.

Khorshidi, G. H., T. Gholizadeh, and A. Naghash. 2014. Consumer Behavior in Relation to the Decision to Buy Green Products: An Investigation on Iranian Consumers. International Journal of Management Perspective 1(3):61-71.

Khosravi, F., U. Jha-Thakur, and T. B. Fischer. 2019. Enhancing EIA systems in developing countries: A focus on capacity development in the case of Iran. The Science of the Total Environment 670:425-32. doi: 10.1016/j.scitotenv.2019.03.195.

Kiatkawsin, K., and H. Han. 2017. Young travelers' intention to behave pro-environmentally: Merging the value-beliefnorm theory and the expectancy theory. Tourism Management 59:76-88. doi: 10.1016/j.tourman.2016.06.018.

Klöckner, C. A. 2013. A comprehensive model of the psychology of environmental behaviour-A meta-analysis. Global Environmental Change 23 (5):1028-38. doi: 10. 1016/j.gloenvcha.2013.05.014.

Klöckner, C. A., and A. Blöbaum. 2010. A comprehensive action determination model: Toward a broader understanding of ecological behavior using the example of travel mode choice. Journal of Environmental Psychology 30 (4):574-86. doi: 10.1016/j.jenvp.2010.03.001.

Kurz, T., M. Linden, and N. Sheehy. 2007. Attitudinal and community influences on participation in new curbside recycling initiatives in Northern Ireland. Environment and Behavior 39 (3):367-91. doi: 10.1177/0013916506294152.

Kusago, T., and B. L. Barham. 2001. Preference Heterogeneity, Power, and Intrahousehold DecisionMaking in Rural Malaysia. World Development 29 (7): 1237-56. https://doi.org/10.1016/S0305-750X. (01)000316 doi: 10.1016/S0305-750X(01)00031-6.

Lanzini, P. 2018. Responsible Citizens and Sustainable Consumer Behavior: New Interpretive Frameworks. Abingdon, UK: Routledge.

Lanzini, P., and S. A. Khan. 2017. Shedding light on the psychological and behavioral determinants of travel mode choice: A meta-analysis. Transportation Research Part F:
Traffic Psychology and Behaviour 48:13-27. doi: 10.1016/j. trf.2017.04.020.

Lanzini, P., D. Pinheiro, and E. Jara. 2018. Sustainable Mobility in Florianópolis: A Commuter-Based Empirical Investigation. Department of Management, Università Ca' Foscari Venezia Working Paper No. 2018/01. Available at SSRN: https://ssrn.com/abstract $=3107297$ or doi: 10.2139 / ssrn.3107297.

Lee, C. 1991. Modifying an American Consumer Behavior Model for Consumers in Confucian Culture: The Case of Fishbein Behavioral Intentions Model. Journal of International Consumer Marketing 3 (1):27-50. doi: 10. 1300/J046v03n01_03.

Liobikienè, G., J. Mandravickaite, and J. Bernatonienè. 2016. Theory of planned behavior approach to understand the green purchasing behavior in the EU: A cross-cultural study. Ecological Economics 125:38-46. doi: 10.1016/j.ecolecon.2016.02.008.

Liu, W., P. Oosterveer, and G. Spaargaren. 2016. Promoting sustainable consumption in China: A conceptual framework and research review. Journal of Cleaner Production 134:13-21. doi: 10.1016/j.jclepro.2015.10.124.

Mahadin, B. 2018. Factors Affecting Customer Switching Behavior towards Hybrid Electrical Vehicles (HEV's) from a Customer Perspective in Jordan. European Journal of Marketing and Economics 1 (3):53-65. doi: 10.26417/ ejme.v1i3.p53-65.

Makki, M. H., F. Abd-El-Khalick, and S. BouJaoude. 2003. Lebanese secondary school students' environmental knowledge and attitudes. Environmental Education Research 9 (1):21-33. doi: 10.1080/13504620303468.

Mancha, R. M., and C. Y. Yoder. 2015. Cultural antecedents of green behavioral intent: An environmental theory of planned behavior. Journal of Environmental Psychology 43:145-54. doi: 10.1016/j.jenvp.2015.06.005.

Mattar, L., M. G. Abiad, A. Chalak, M. Diab, and H. Hassan. 2018. Attitudes and Behaviors Shaping Household Food Waste Generation: Lessons from Lebanon. Journal of Cleaner Production 198:1219-23. doi: 10.1016/j.jclepro.2018.07.085.

McDaniel, S. W., and J. J. Burnett. 1990. Consumer religiosity and retail store evaluative criteria. Journal of the Academy of Marketing Science 18 (2):101-12. doi: 10. 1007/BF02726426.

Miafodzyeva, S., and N. Brandt. 2013. Recycling behaviour among householders: Synthesizing determinants via a meta-analysis. Waste and Biomass Valorization 4 (2): 221-35. doi: 10.1007/s12649-012-9144-4.

Michel, Z., K. Nancy, and H. Atef. 2014. Green Mobile Telecommunication: Assessment and Implementation a Consumer Perspective in Lebanon. Global Journal of Technology and Optimization 5 (1):2.

Minbashrazgah, M. M., F. Maleki, and M. Torabi. 2017. Green chicken purchase behavior: The moderating role of price transparency. Management of Environmental Quality: An International Journal 28 (6):902-16. doi: 10. 1108/MEQ-12-2016-0093. 
Minton, E. A., N. Spielmann, L. R. Kahle, and C. H. Kim. 2018. The subjective norms of sustainable consumption: A cross-cultural exploration. Journal of Business Research 82:400-8. doi: 10.1016/j.jbusres.2016.12.031.

Mkik, S., M. Khouilid, and A. Aomari. 2017. Green Advertising and Environmentally Consumption: The Level of Awareness and Moroccan Costumer's. Perception. IOSR Journal of Business and Management, International Organization of Scientific Research 19 (8): $1-11$.

Mobrezi, H., and B. Khoshtinat. 2016. Investigating the Factors Affecting Female Consumers' Willingness toward Green Purchase Based on the Model of Planned Behavior. Procedia Economics and Finance 36:441-7. https://doi.org/10.1016/S2212-5671. (16)30062-4 doi: 10. 1016/S2212-5671(16)30062-4.

Mohamed, M.,. A. Chymis, and A. Shelaby. 2012. Determinants of organic food consumption in Egypt. International Journal of Economics and Business Modeling 3 (3):183-91.

Moon, M. A., S. H. Mohel, and A. Farooq. 2020. I green, you green, we all green: Testing the extended environmental theory of planned behavior among the university students of Pakistan. The Social Science Journal, 1-17. doi: 10.1016/j.soscij.2019.05.001

Morren, M., and A. Grinstein. 2016. Explaining environmental behavior across borders: A meta-analysis. Journal of Environmental Psychology 47:91-106. doi: 10.1016/j. jenvp.2016.05.003.

Mostafa, M. M. 2006. Antecedents of Egyptian consumers' green purchase intentions: A hierarchical multivariate regression model. Journal of International Consumer Marketing 19 (2):97-126. doi: 10.1300/J046v19n02_06.

Mostafa, M. M. 2007. A hierarchical analysis of the green consciousness of the Egyptian consumer. Psychology and Marketing 24 (5):445-73. doi: 10.1002/mar.20168.

Mostafa, M. M. 2009. Shades of green: A psychographic segmentation of the green consumer in Kuwait using selforganizing maps. Expert Systems with Applications 36 (8): 11030-8. doi: 10.1016/j.eswa.2009.02.088.

Mostafa, M. M. 2016. Egyptian consumers' willingness to pay for carbon-labeled products: A contingent valuation analysis of socio-economic factors. Journal of Cleaner Production 135:821-8. doi: 10.1016/j.jclepro.2016.06.168.

Mostafa, M. M., and M. Al-Hamdi. 2016. Kuwaiti consumers' willingness to pay for environmental protection in Failaka island: A contingent valuation analysis. Tourism Review 71 (3):219-33. doi: 10.1108/TR-05-2016-0012.

Mourad, M., and Y. Serag Eldin Ahmed. 2012. Perception of green brand in an emerging innovative market. European Journal of Innovation Management 15 (4): 514-37. doi: 10.1108/14601061211272402.

Muhammad, S., E. Fathelrahman, and R. Ullah. 2015. Factors affecting consumers' willingness to pay for certified organic food products in United Arab Emirates. Journal of Food Distribution Research 46 (1):37-45.
Nahiduzzaman, K. M., A. S. Aldosary, A. S. Abdallah, M. Asif, H. W. Kua, and A. M. Alqadhib. 2018. Households energy conservation in Saudi Arabia: Lessons learnt from change-agents driven interventions program. Journal of Cleaner Production 185:998-1014. doi: 10.1016/j.jclepro. 2018.03.052.

Nassani, A. M., J. Ahmad Khader, M. Abd-el Moemen, and I. Ali. 2013. Consumer environmental activism, sustainable consumption behavior and satisfaction with life. Life Science Journal 10 (2):1000-6.

Nedra, B. A., S. Sharma, and A. Dakhli. 2015. Perception and motivation to purchase organic products in Mediterranean countries: An empirical study in Tunisian context. Journal of Research in Marketing and Entrepreneurship 17 (1):67-90. doi: 10.1108/JRME-072014-0015.

Nejati, M., Y. Salamzadeh, and A. Salamzadeh. 2011. Ecological purchase behavior: Insights from a Middle Eastern country. International Journal of Environment and Sustainable Development 10 (4):417-32. doi: 10.1504/ IJESD.2011.047774.

Nguyen, T. T. P., D. Zhu, and N. P. Le. 2015. Factors influencing waste separation intention of residential households in a developing country: Evidence from Hanoi, Vietnam. Habitat International 48:169-76. doi: 10.1016/j. habitatint.2015.03.013.

Oliver, R. L. 1980. A Cognitive Model of the Antecedents and Consequences of Satisfaction Decisions. Journal of Marketing Research 17 (4):460-9. doi: 10.1177/ 002224378001700405.

Oweini, A., and A. Houri. 2006. Factors Affecting Environmental Knowledge and Attitudes among Lebanese College Students. Applied Environmental Education \& Communication 5 (2):95-105. doi: 10.1080/ 15330150600648945.

Pakpour, A. H., I. M. Zeidi, M. M. Emamjomeh, S. Asefzadeh, and H. Pearson. 2014. Household waste behaviours among a community sample in Iran: an application of the theory of planned behaviour. Waste Management (New York, N.Y.) 34 (6):980-6. doi: 10. 1016/j.wasman.2013.10.028.

Papaoikonomou, E., G. Ryan, and M. Valverde. 2011. Mapping ethical consumer behavior: Integrating the empirical research and identifying future directions. Ethics \& Behavior 21 (3):197-221. doi: 10.1080/10508422. 2011.570165.

Prakash, G., and P. Pathak. 2017. Intention to buy ecofriendly packaged products among young consumers of India: A study on developing nation. Journal of Cleaner Production 141:385-93. doi: 10.1016/j.jclepro.2016.09.116.

Rahnama, H. 2017. Effect of Consumption Values on Women's Choice Behavior Toward Organic Foods: The Case of Organic Yogurt in Iran. Journal of Food Products Marketing 23 (2):144-66. doi: 10.1080/10454446.2017. 1244790.

Rahnama, H., and S. Rajabpour. 2017. Identifying effective factors on consumers' choice behavior toward green 
products: the case of Tehran, the capital of Iran. Environmental Science and Pollution Research International 24 (1):911-25. doi: 10.1007/s11356-0167791-x.

Rezaei, R., and M. Ghofranfarid. 2018. Rural households' renewable energy usage intention in Iran: Extending the unified theory of acceptance and use of technology. Renewable Energy. 122:382-91. doi: 10.1016/j.renene.2018. 02.011 .

Rice, G. 2006. Pro-environmental behavior in Egypt: Is there a role for Islamic environmental ethics? Journal of Business Ethics 65 (4):373-90. doi: 10.1007/s10551-0060010-9.

Rivis, A., P. Sheeran, and C. J. Armitage. 2009. Expanding the affective and normative components of the theory of planned behavior: A meta-analysis of anticipated affect and moral norms. Journal of Applied Social Psychology 39 (12):2985-3019. doi: 10.1111/j.1559-1816.2009.00558.x.

Ruby, M. B., I. Walker, and H. M. Watkins. 2020. Sustainable consumption: The psychology of individual choice, identity, and behavior. Journal of Social Issues 76 (1):8-18. doi: 10.1111/josi.12376.

Ryan, R. M., and E. L. Deci. 2000. Self-determination theory and the facilitation of intrinsic motivation, social development, and well-being. The American Psychologist 55 (1):68-78. doi: 10.1037//0003-066x.55.1.68.

Sadati, S. A., and Y. Mohammadi. 2012. Key Values Influence Consumer Intention towards Organic Food in Iran. Research Journal of Applied Sciences, Engineering and Technology 4 (14):2055-60.

Saleki, Z. S., M. S. Seyedeh, and M. R. Rahimi. 2012. Organic food purchasing behavior in Iran. International Journal of Business and Social Science 3(13):278.

Sarkis, A. M. 2017. A comparative study of theoretical behaviour change models predicting empirical evidence for residential energy conservation behaviours. Journal of Cleaner Production 141:526-37. doi: 10.1016/j.jclepro. 2016.09.067.

Scalco, A., S. Noventa, R. Sartori, and A. Ceschi. 2017. Predicting organic food consumption: A meta-analytic structural equation model based on the theory of planned behavior. Appetite 112:235-48. doi: 10.1016/j.appet.2017. 02.007 .

Schahn, J., and E. Holzer. 1990. Studies of individual environmental concern: The role of knowledge, gender, and background variables. Environment and Behavior 22 (6): 767-86. doi: 10.1177/0013916590226003.

Schanes, K., K. Dobernig, and B. Gözet. 2018. Food waste matters - A systematic review of household food waste practices and their policy implications. Journal of Cleaner Production 182:978-91. doi: 10.1016/j.jclepro.2018.02.030.

Schneider, H., J. Krieger, and A. Bayraktar. 2011. The Impact of Intrinsic Religiosity on Consumers' Ethical Beliefs: Does It Depend on the Type of Religion? A Comparison of Christian and Moslem Consumers in Germany and Turkey. Journal of Business Ethics 102 (2): 319-32. doi: 10.1007/s10551-011-0816-y.
Schwartz, S. H., and J. A. Howard. 1981. A normative decision-making model of altruism. In J.P. Rushton \& R.M. Sorrentino (Eds.), Altruism and helping behavior, 189-211. Hillsdale, NJ: Lawrence Erlbaum.

Sen, S., S. Du, and C. B. Bhattacharya. 2016. Corporate social responsibility: A consumer psychology perspective. Current Opinion in Psychology 10:70-5. doi: 10.1016/j. copsyc.2015.12.014.

Sharif, K. 2016. Investigating the key determinants of Muslim ethical consumption behavior amongst affluent Qataris. Journal of Islamic Marketing 7 (3):303-30. doi: 10.1108/JIMA-01-2015-0001.

Siyavooshi, M., A. Foroozanfar, and Y. Sharifi. 2019. Effect of Islamic values on green purchasing behavior. Journal of Islamic Marketing 10 (1):125-37. doi: 10.1108/JIMA05-2017-0063.

Steg, L., and C. Vlek. 2009. Encouraging pro-environmental behaviour: An integrative review and research agenda. Journal of Environmental Psychology 29 (3):309-17. doi: 10.1016/j.jenvp.2008.10.004.

Stern, P. C. 2000. New environmental theories: Toward a coherent theory of environmentally significant behavior. Journal of Social Issues 56 (3):407-24. doi: 10.1111/00224537.00175.

Stern, P. C., T. Dietz, T. D. Abel, G. A. Guagnano, and L. Kalof. 1999. A value-belief-norm theory of support for social movements: The case of environmentalism. Human Ecology Review 6 (2):81-97.

Strydom, W. F. 2018. Applying the theory of planned behavior to recycling behavior in South Africa. Recycling 3 (3):43. doi: 10.3390/recycling3030043.

Taljaard, H., N. C. Sonnenberg, and B. M. Jacobs. 2018. Factors motivating male consumers' eco-friendly apparel acquisition in the South African emerging market. International Journal of Consumer Studies 42 (5):461-8. doi: $10.1111 /$ ijcs.12441.

Tamer, A. 2011. Environmental segmentation alternatives: Buyers' profiles and implications. Journal of Islamic Marketing 2 (1):55-73. doi: 10.1108/17590831111115240.

Thøgersen, J. 2010. Country Differences in Sustainable Consumption: The Case of Organic Food. Journal of $\begin{array}{llll}\text { Macromarketing } \quad 30 & \text { (2):171-85. doi: 10.1177/ }\end{array}$ 0276146710361926.

Thøgersen, J., and F. Ölander. 2003. Spillover of environment-friendly consumer behavior. Journal of Environmental Psychology 23 (3):225-36. https://doi.org/ 10.1016/S0272-4944(03)00018-5 doi: 10.1016/S02724944(03)00018-5.

Tranfield, D., D. Denyer, and P. Smart. 2003. Towards a methodology for developing evidence-informed management knowledge by means of systematic review. British Journal of Management 14 (3):207-22. doi: 10.1111/14678551.00375.

Triandis, H. C. 1977. Interpersonal behavior. California: Brooks/Cole Pub. Co.

Tripathi, A., and M. P. Singh. 2016. Determinants of sustainable/green consumption: A review. International 
Journal of Environmental Technology and Management 19 (3/4):316-58. doi: 10.1504/IJETM.2016.082258.

United Nations. 2018. Goal 12: Ensure sustainable consumption and production patterns. Retrieved from https://www.un.org/sustainabledevelopment/sustainableconsumption-production/

Vazifehdoust, H., M. Taleghani, F. Esmaeilpour, K. Nazari, and M. Khadang. 2013. Purchasing green to become greener: Factors influence consumers' green purchasing behavior. Management Science Letters 3 (9):2489-500. doi: $10.5267 /$ j.msl.2013.08.013.

Verplanken, B., and H. Aarts. 1999. Habit, attitude, and planned behavior: Is habit an empty construct or an interesting case of goal-directed automaticity?. European Review of Social Psychology 10 (1):101-34. doi: 10.1080/ 14792779943000035.

Wang, C., P. Ghadimi, M. K. Lim, and M. L. Tseng. 2019. A literature review of sustainable consumption and production: A comparative analysis in developed and developing economies. Journal of Cleaner Production 206: 741-54. doi: 10.1016/j.jclepro.2018.09.172.

Wells, V. K., B. Taheri, D. Gregory-Smith, and D. Manika. 2016. The role of generativity and attitudes on employees home and workplace water and energy saving behaviors. Tourism Management 56:63-74. doi: 10.1016/j.tourman. 2016.03.027.

Wu, C-s, X-x Zhou, and M. Song. 2016. Sustainable consumer behavior in China: An empirical analysis from the Midwest regions. Journal of Cleaner Production 134: 147-65. doi: 10.1016/j.jclepro.2015.06.057.

Yadav, R., and G. S. Pathak. 2016. Young consumers' intention towards buying green products in a developing nation: Extending the theory of planned behavior. Journal of Cleaner Production 135:732-9. doi: 10.1016/j. jclepro.2016.06.120.

Yadav, R., and G. S. Pathak. 2017. Determinants of Consumers' Green Purchase Behavior in a Developing Nation: Applying and Extending the Theory of Planned
Behavior. Ecological Economics 134:114-22. doi: 10.1016/j. ecolecon.2016.12.019.

Yaghi, A., and M. Alibeli. 2017. Theoretical and empirical analysis of citizens' willingness to pay: Ethical and policy implications for the environment in the United Arab Emirates. Public Integrity 19 (1):41-57. doi: 10.1080/ 10999922.2016.1200409.

Yang, S., L. Li, and J. Zhang. 2018. Understanding consumers' sustainable consumption intention at china's double11 online shopping festival: An extended theory of planned behavior model. Sustainability 10 (6):1801. doi: 10.3390/su10061801.

Yazdanpanah, M., and M. Forouzani. 2015. Application of the Theory of Planned Behavior to predict Iranian students' intention to purchase organic food. Journal of Cleaner Production 107:342-52. doi: 10.1016/j.jclepro. 2015.02.071.

Yazdanpanah, M., M. Forouzani, and M. Hojjati. 2015. Willingness of Iranian young adults to eat organic foods: Application of the Health Belief Model. Food Quality and Preference 41:75-83. doi: 10.1016/j.foodqual.2014.11.012.

Yazdanpanah, M., N. Komendantova, Z. N. Shirazi, and J. Linnerooth-Bayer. 2015. Green or in between? Examining youth perceptions of renewable energy in Iran. Energy Research \& Social Science 8:78-85. doi: 10.1016/j.erss. 2015.04.011.

Zare, P. N., A. Bagheri, and K. P. Moein. 2016. Reviewing and ranking the factors affecting the attitude, intention and behavior of consumers green purchasing. International Business Management 10 (15):3223-9.

Zarei, A., and F. Maleki. 2018. From Decision to Run: The Moderating Role of Green Skepticism. Journal of Food Products Marketing 24 (1):96-116. doi: 10.1080/10454446. 2017.1266548.

Zu'bi, M., H. Al-Dmour, M. Al-Shami, and R. Nimri. 2015. Integrated Green Purchase Model: An Empirical Analysis on Jordan. International Journal of Operations and Logistics Management 4 (2):139-51. 